Research Article

\title{
Parallel Offset Crack Interactions in Rock under Unloading Conditions
}

\author{
Zihan Zhou iD and Zhonghui Chen \\ School of Mechanics and Civil Engineering, China University of Mining and Technology, Beijing 100083, China \\ Correspondence should be addressed to Zihan Zhou; 18813027369@163.com
}

Received 3 July 2019; Revised 5 September 2019; Accepted 24 September 2019; Published 16 November 2019

Academic Editor: Hongchao Kou

Copyright (c) 2019 Zihan Zhou and Zhonghui Chen. This is an open access article distributed under the Creative Commons Attribution License, which permits unrestricted use, distribution, and reproduction in any medium, provided the original work is properly cited.

\begin{abstract}
Rock slopes contain numerous nonpenetrating intermittent joints which maintain stability under excavation disturbance. The tip interaction coefficient (IC) of parallel offset double cracks in a typical rock mass under unloading conditions was calculated in this study based on the superposition principle and fracture mechanics to determine the meso-influence law of intermittent joint interaction in the slope under the action of excavation. The influence of many factors on the said interaction was also analyzed theoretically. Lateral unloading tests were conducted on rock-like specimens with parallel offset cracks in addition to RFPA ${ }^{2 \mathrm{D}}$ numerical simulation and theoretical analysis. The results show that a smaller length of rock bridge or staggered distance between the cracks results in more severe and sensitive interactions at the crack tip. The Type I interaction strength of the tip of the crack is not affected by the inclination angle of the crack, but shear failure gradually weakens as the angle changes. The shear failure of the tip of the crack is more sensitive to changes in the inclination angle when the cracks are closer to each other; the change is the most intense when $\alpha$ is about $60^{\circ}$. Lateral unloading test and RFPA ${ }^{2 \mathrm{D}}$ numerical simulation results are in close agreement with the theoretical analysis, which validates the theoretical results. The current study shows the interaction of the parallel offset cracks in rock under unloading conditions and is conducive to the study of the meso-failure mechanism of the jointed rock slope in an open-pit mine under the action of excavation.
\end{abstract}

\section{Introduction}

An open-pit mine slope is subjected to rock mass unloading in the process of excavation. Numerous nonpenetrating intermittent joints in the rock slope control the strength of the rock mass and the failure mode of the slope. High stress concentration at the end of the intermittent joint may lead to the initiation, propagation, and penetration of cracks in the rock bridge which may ultimately cause sudden instability and macroscopic failure of the slope, and the rock slope instability mechanisms occur not only along existing discontinuities but also as complex internal processes associated with shear or tensile fracture in the intact rock, particularly in massive natural rock slopes and deep engineered slopes [1-3]. Meso-mechanical knowledge regarding the crack evolution laws and interaction between cracks and intermittent joints in the rock mass have crucial significance in terms of the failure mechanism of open-pit rock slopes under excavation. Such knowledge can be utilized to design safe, reasonable excavation schemes.

Many scholars have explored the meso-failure mechanism of rock masses with joints and on-site rock cracking behaviors. Sagong et al. [4-7], for example, analyzed the failure mode of a cracked rock mass under loading and found that the geometric distribution of cracks, confining pressure, and inertia effect of dynamic loads influence failure in different ways. Tang et al. [8-10] studied the brittle fracture of rock with an angled crack under combined tensile and compressive loading conditions by using linear elastic fracture mechanics (LEFM) and clarified the influence of the confining pressure, the presence of friction on the flaw surface, and the nonsingular stresses (T-stresses) both parallel $\left(\mathrm{T}_{x}\right)$ and perpendicular $\left(\mathrm{T}_{y}\right)$ to the crack plane on crack initiation. Tang et al. [11] analyzed the mechanism of 
crack generation and propagation in a rock mass with intermittent joints as per the effects of intermittent joint distribution and interactions using $\mathrm{RFPA}^{2 \mathrm{D}}$ software. Wong and Chau [12] used sandstone-like simulation materials with various microcracks to study the penetration mechanism of preset crack samples with different angular distributions. Bobet and Einstein [13] carried out uniaxial compression tests on rock-like specimens with two or three parallel preset cracks and analyzed the crack penetration mechanism of secondary crack initiation, propagation, and confluence. Haeri et al. [14] performed a coupled numerical-experimental analysis of crack propagation, crack coalescence, and breaking process of jointed rock slopes by studying the mechanical behavior of precracked brittle substances considering the specially prepared rock-like specimens and natural rock slopes, simultaneously. Zhao et al. [15] investigated the cracking and stress-strain behavior, especially the local strain concentration near the flaw tips, of rock-like material containing two flaws by a series of uniaxial compression tests. Jiang et al. [16, 17] developed an intelligent optimization method for cavern excavation to improve the underground engineering's stability and described the basic unloading performances of shear belts induced by excavation through observational data and numerical back analysis during the construction of Laxiwa hydraulic station which is a typical hard rock, with high compressive strength and elasto-brittle failure modes, such as spalling and slabbing.

There have been few previous studies on the propagation and evolution of parallel offset cracks and the interaction between cracks under unloading conditions, and most extant research centers on rock specimen testing and numerical simulation. There is yet a lack of theoretical quantitative research. In addition, by reading a large number of relevant literature, it is found that there is almost no feasible and effective method with a small amount of calculation to calculate the SIF at the crack tip of rock mass with multiple cracks. Therefore, in the present study, based on the stress circle theory in material mechanics and the relevant calculation method of SIF in fracture mechanics, the SIFs of parallel offset crack tips under uniaxial tension and uniaxial compression were calculated, respectively, by using the method of multiple superposition, and then the SIFs of crack tips under unloading conditions were determined, which greatly reduced the complexity of the calculation. What is more, this paper also defined the ratio of the SIF at the crack tip in the stress state of the rock mass with double cracks under unloading conditions to that in the stress state of the rock mass with single crack under unloading conditions as the interaction coefficient (IC). And the interactions among parallel offset double cracks under unloading conditions were investigated by using IC which was served as the quantitative evaluation index. Finally, the theoretical results were validated by comparison against lateral unloading test and $\mathrm{RFPA}^{2 \mathrm{D}}$ numerical simulation results for similar rock-like materials.

\section{Parallel Offset Double Crack SIF Calculations}

2.1. Mechanics Model of Parallel Offset Double Cracks under Unloading Conditions. Huang [18] found that the rock mass stress field in the slope body is redistributed after excavation. A secondary stress field appears in the distribution characteristics of the stress reduction zone (C), stress increase zone (B), and original rock stress zone (A), as shown in Figure 1.

Figure 2 shows several closed parallel nonpenetrating intermittent joints in the slope rock mass. A "key block" with two parallel intermittent joints in the slope was selected as the research object here for the sake of simplicity. The "key block" is subjected to horizontal and vertical in situ stress before excavation, and the stress path changes after excavation. The vertical direction is continually affected by in situ stress; however, the horizontal direction stress pattern transforms from compressive to tensile. The stress state of the rock mass is initially compressive-shear and becomes tensile-shear $[18,19]$.

The stress state of the rock mass with cracks under unloading conditions is too complex to effectively analyze under crack theory alone. According to the superposition principle, on the basis of online elastic mechanics, under the same boundary conditions, the total stress field caused by two or more different loading systems near the crack tip can be obtained by the algebra of each SIF [20, 21]. Here, the stress state was also analyzed under the superposition principle, as shown in Figure 3, the stress state A of the rock mass with cracks under unloading conditions is decomposed into the stress state B under uniaxial tension and stress state $\mathrm{D}$ under uniaxial compression. The numbers in the figure represent the number of cracks, and states $\mathrm{B}$ and $\mathrm{C}$ are equivalent, where $\beta=90^{\circ}-\alpha$.

According to the above decomposition method shown in Figure 3, it can be concluded that the SIFs of the rock mass with parallel offset double cracks under unloading conditions are

$$
K^{\mathrm{A}}=K^{\mathrm{B}}+K^{\mathrm{D}}=K^{\mathrm{C}}+K^{\mathrm{D}}
$$

where $K^{\mathrm{B}}$ and $K^{\mathrm{C}}$ are the SIFs under uniaxial tension and $K^{\mathrm{D}}$ is the SIF under uniaxial compression. In this paper, $K^{\mathrm{C}}$ and $K^{\mathrm{D}}$ are calculated based on the equivalent superposition method.

2.2. Calculation of SIFs $\left(K^{C}\right)$ under Uniaxial Tension. The "key block" in the jointed rock mass of the slope can be regarded as an infinite plate with parallel offset double cracks. As shown in Figure 4, the vertical action of the plate is uniformly distributed on the tensile load $\sigma_{3}$, the center contains two parallel offset cracks, the crack inclination angle is $\beta$, and the lengths of Crack 1 and Crack 2 are both $2 a$. The length of the rock bridge and staggered distance between the two cracks are $s$ and $h$, respectively. According to the stress circle theory in material mechanics, the stress state $\mathrm{C}$ of the rock mass under uniaxial tension is in a crack compound form, I and II [22]. The stress state $\mathrm{C}$ can also be made equivalent to the state of vertical tensile stress $\sigma_{\beta}$ and shear stress $\tau_{\beta}$ acting on the crack surface where the far field stress disappears, as shown in Figure 4.

According to the superposition principle, the stress state $\mathrm{C}_{1}$ of the rock mass can be made equivalent to the 


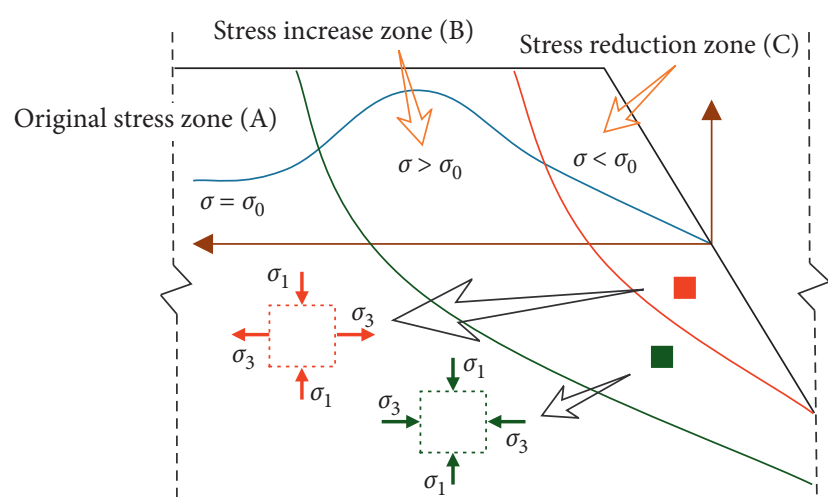

FIGURE 1: Sketch of stresses in different parts of the slope [14].

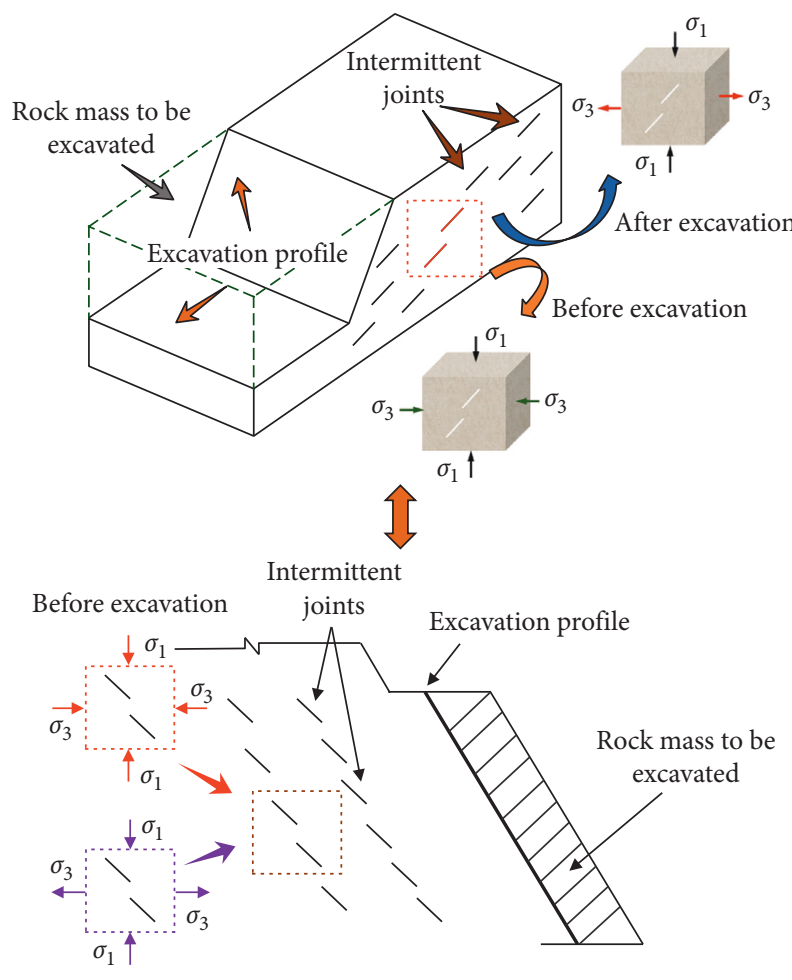

After excavation

Figure 2: Sketch of mechanical models of "key block" in slope before and after excavation.

superposition state of stress state $C_{2}$ and stress state $C_{3}$. The stress state $\mathrm{C}$ of the rock mass under uniaxial tension can then be decomposed into the stress state $\mathrm{C}_{2}$ and the stress state $\mathrm{C}_{3}$ (Figure 4 ). According to the stress circle theory, the vertical stress $\sigma_{\beta}$ and shear stress $\tau_{\beta}$ acting on the crack surface in Figure 4 can be expressed as follows [22, 23]:

$$
\begin{gathered}
\sigma_{\beta}=-\frac{\sigma_{3}}{2}-\frac{\sigma_{3}}{2} \cdot \cos 2 \beta=-\sigma_{3} \cdot \cos ^{2} \beta, \\
\tau_{\beta}=\frac{\sigma_{3}}{2} \cdot \sin 2 \beta=\sigma_{3} \cdot \sin \alpha \cdot \cos \alpha .
\end{gathered}
$$

For the stress state $\mathrm{C}_{2}$ with vertical tensile stress $\sigma_{\beta}$, there are SIFs of Type I and Type II at the crack tips which can be calculated according to formulas (3) and (4), respectively. For the stress state $C_{3}$ with shear stress $\tau_{\beta}$, there are only SIFs of Type I at the crack tips which can be calculated according to formula (5):

$$
\begin{aligned}
& K_{\mathrm{I}}^{\mathrm{C}_{2}}=-F_{\mathrm{I}}^{\mathrm{C}_{2}} \cdot \sigma_{\beta} \cdot \sqrt{\pi a}=F_{\mathrm{I}}^{\mathrm{C}_{2}} \cdot \sigma_{3} \cdot \cos ^{2} \beta \cdot \sqrt{\pi a}, \\
& K_{\mathrm{II}}^{\mathrm{C}_{2}}=-F_{\mathrm{II}}^{\mathrm{C}_{2}} \cdot \sigma_{\beta} \cdot \sqrt{\pi a}=F_{\mathrm{II}}^{\mathrm{C}_{2}} \cdot \sigma_{3} \cdot \cos ^{2} \beta \cdot \sqrt{\pi a}, \\
& K_{\mathrm{II}}^{\mathrm{C}_{3}}=F_{\mathrm{II}}^{\mathrm{C}_{3}} \cdot \tau_{\beta} \cdot \sqrt{\pi a}=F_{\mathrm{II}}^{\mathrm{C}_{3}} \cdot \sigma_{3} \cdot \sin \beta \cdot \cos \beta \cdot \sqrt{\pi a},
\end{aligned}
$$

where $K_{\mathrm{I}}^{\mathrm{C}_{2}}, K_{\mathrm{II}}^{\mathrm{C}_{2}}$, and $K_{\mathrm{II}}^{\mathrm{C}_{3}}$ are SIFs of Type I or Type II at the crack tip in the stress states $\mathrm{C}_{2}$ and $\mathrm{C}_{3}$, respectively; $F_{\mathrm{I}}^{\mathrm{C}_{2}}, F_{\mathrm{II}}^{\mathrm{C}_{2}}$, and $F_{\text {II }}^{\mathrm{C}_{3}}$ are the geometric correlation coefficients of SIFs related to crack distribution, which are related to the crack length, the length of rock bridge, and the staggered distance between cracks; and the values of $F_{\mathrm{I}}^{\mathrm{C}_{2}}, F_{\mathrm{II}}^{\mathrm{C}_{2}}$, and $F_{\mathrm{II}}^{\mathrm{C}_{3}}$ can be determined by consulting the appendix or reference [24]. The SIF at the crack tip under uniaxial tension can be expressed as follows:

$$
\begin{aligned}
K_{\mathrm{I}}^{\mathrm{C}}= & K_{\mathrm{I}}^{\mathrm{C}_{2}}=F_{\mathrm{I}}^{\mathrm{C}_{2}} \cdot \sigma_{3} \cdot \cos ^{2} \beta \cdot \sqrt{\pi a}, \\
K_{\mathrm{II}}^{\mathrm{C}}= & K_{\mathrm{II}}^{\mathrm{C}_{2}}+K_{\mathrm{II}}^{\mathrm{C}_{3}}=\left(F_{\mathrm{II}}^{\mathrm{C}_{2}} \cdot \cos ^{2} \beta+F_{\mathrm{II}}^{\mathrm{C}_{3}} \cdot \sin \beta \cdot \cos \beta\right) \\
& \cdot \sigma_{3} \cdot \sqrt{\pi a} .
\end{aligned}
$$

2.3. Calculation of SIFs $\left(K^{D}\right)$ under Uniaxial Compression. Unlike the tension-shear state, the parallel offset cracks in the compression-shear state are subjected to normal pressure, and the cracks may even be closed under pressure. There are only SIFs of Type II at the crack tips, so $K_{\mathrm{I}}^{\mathrm{D}_{2}}=0$. As shown in Figure 5, the stress state $\mathrm{D}$ of the rock mass under uniaxial compression can be made equivalent to the stress state $D_{1}$. The stress state $D_{1}$ can be made equivalent to the superposition of stress state $\mathrm{D}_{2}$ and stress state $\mathrm{D}_{3}$, so $K^{\mathrm{D}}=K^{\mathrm{D}_{1}}+$ $K^{\mathrm{D}_{2}}+K^{\mathrm{D}_{3}}$. The SIF at the crack tip under uniaxial compression can be expressed as follows:

$$
\begin{aligned}
K_{\mathrm{I}}^{\mathrm{D}}= & K_{\mathrm{I}}^{\mathrm{D}_{2}}=0, \\
K_{\mathrm{II}}^{\mathrm{D}}= & K_{\mathrm{II}}^{\mathrm{D}_{2}}+K_{\mathrm{II}}^{\mathrm{D}_{3}}=-\left(F_{\mathrm{II}}^{\mathrm{D}_{2}} \cdot \cos ^{2} \alpha+F_{\mathrm{II}}^{\mathrm{D}_{3}} \cdot \sin \alpha \cdot \cos \alpha\right) \\
& \cdot \sigma_{1} \cdot \sqrt{\pi a},
\end{aligned}
$$

where $K_{\mathrm{I}}^{\mathrm{D}_{2}}, K_{\mathrm{II}}^{\mathrm{D}_{2}}$, and $K_{\mathrm{II}}^{\mathrm{D}_{3}}$ are SIFs of Type I or Type II at the crack tip in the stress states $\mathrm{D}_{2}$ and $\mathrm{D}_{3}$, respectively; $F_{\mathrm{I}}^{\mathrm{D}_{2}}, F_{\mathrm{II}} \mathrm{D}_{2}$, and $F_{\mathrm{II}}^{\mathrm{D}_{3}}$ are the geometric correlation coefficients of SIFs related to crack distribution and crack length. The values of $F_{\mathrm{I}}^{\mathrm{D}_{2}}, F_{\mathrm{II}}^{\mathrm{D}_{2}}$, and $F_{\mathrm{II}}^{\mathrm{D}_{3}}$ in the stress states $\mathrm{D}_{2}$ and $\mathrm{D}_{3}$ can be determined by consulting the appendix or reference [24].

2.4. Calculation of SIFs $\left(K^{A}\right)$ of Double Cracks under Unloading Condition. Substituting formulas (6) and (7) into (1) yields the following expression of the SIF $\left(K^{\mathrm{A}}\right)$ at the crack tip under unloading conditions:

$$
\begin{aligned}
K_{\mathrm{I}}^{\mathrm{A}}= & K_{\mathrm{I}}^{\mathrm{C}}+K_{\mathrm{I}}^{\mathrm{D}}=F_{\mathrm{I}}^{\mathrm{C}_{2}} \cdot \sigma_{3} \cdot \cos ^{2} \beta \cdot \sqrt{\pi a}, \\
K_{\mathrm{II}}^{\mathrm{A}}= & K_{\mathrm{II}}^{\mathrm{C}}+K_{\mathrm{II}}^{\mathrm{D}}=\left[\left(F_{\mathrm{II}}^{\mathrm{C}_{2}} \cdot \cos ^{2} \beta+F_{\mathrm{II}}^{\mathrm{C}_{3}} \cdot \sin \beta \cdot \cos \beta\right)\right. \\
& \left.\cdot \sigma_{3}-\left(F_{\mathrm{II}}^{\mathrm{D}_{2}} \cdot \cos ^{2} \alpha+F_{\mathrm{II}}^{\mathrm{D}_{3}} \cdot \sin \alpha \cdot \cos \alpha\right) \cdot \sigma_{1}\right] \cdot \sqrt{\pi a},
\end{aligned}
$$




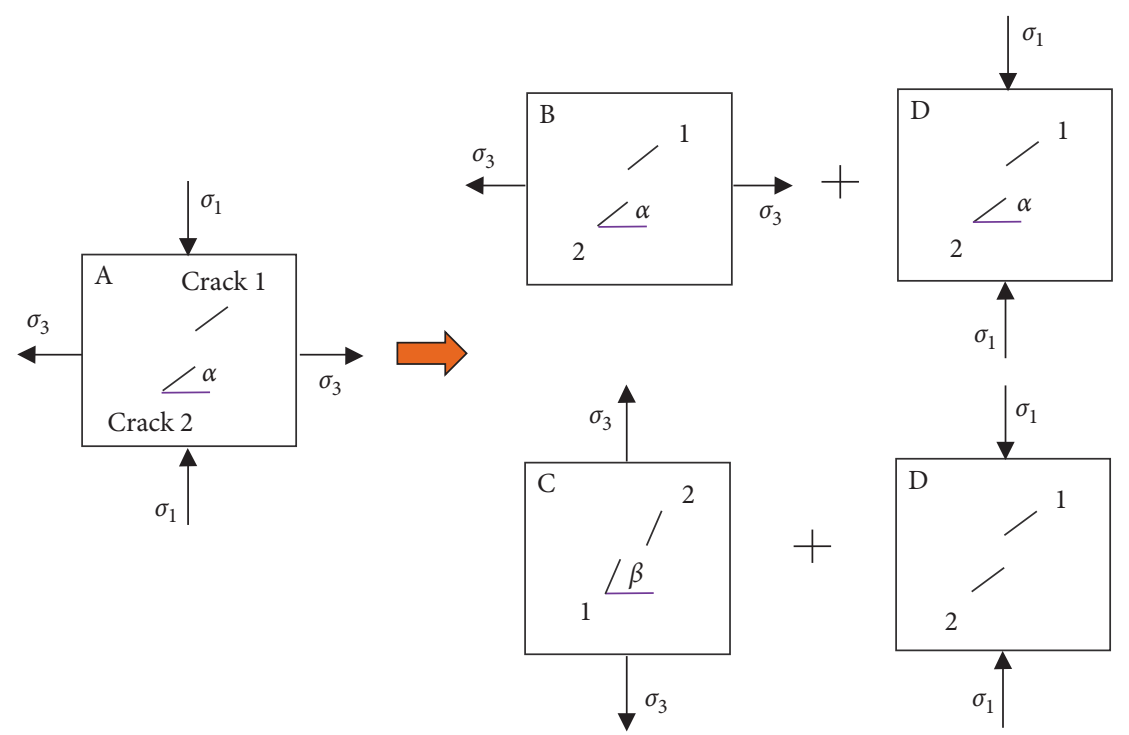

FIgURE 3: Superposition method of stress state of rock mass with double cracks under unloading conditions.
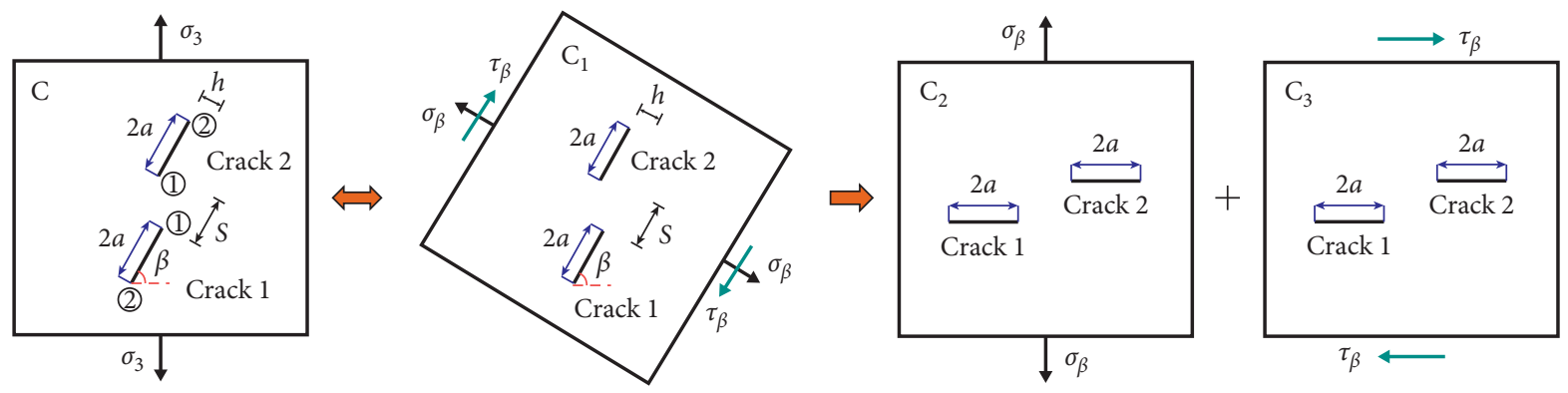

FIGURE 4: Equivalent sketch of the stress state (C) of rock mass under uniaxial tension.
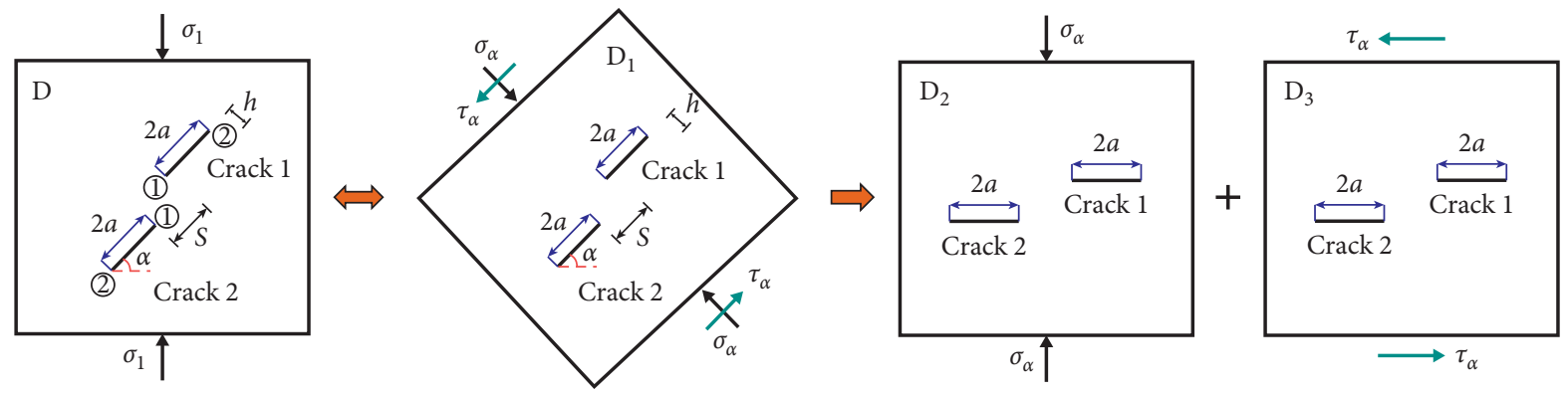

FIGURE 5: Equivalent sketch of the stress state (D) of rock mass under uniaxial compression.

where $K_{\mathrm{I}}^{\mathrm{A}}$ and $K_{\mathrm{II}}^{\mathrm{A}}$ are SIFs of Type I or Type II at the crack tip under unloading conditions.

\subsection{Calculation of SIFs $\left(K^{E}\right)$ of Single Crack under Unloading} Conditions. The SIF of a single crack under unloading conditions is determined similarly as double cracks. The superposition method shown in Figure 6 can be used to solve the SIF of the rock mass with a single crack under unloading conditions, that is, $K^{\mathrm{E}}=K^{\mathrm{F}}+K^{\mathrm{G}}$, where $K^{\mathrm{F}}$ and $K^{\mathrm{G}}$ are calculated according to the decomposition method shown in Figures 7 and 8 (not described in detail here).
The SIF of the crack tip in the stress state of the rock mass with a single crack under unloading conditions can be expressed as follows:

$$
\begin{aligned}
K_{\mathrm{I} 0}^{\mathrm{E}}= & K_{\mathrm{I} 0}^{\mathrm{F}_{1}}+K_{\mathrm{I} 0}^{\mathrm{G}_{1}}=\sigma_{3} \cdot \cos ^{2} \beta \cdot \sqrt{\pi a}, \\
K_{\mathrm{II} 0}^{\mathrm{E}}= & K_{\mathrm{II} 0}^{\mathrm{F}_{1}}+K_{\mathrm{II} 0}^{\mathrm{G}_{1}}=\left(\sigma_{3} \cdot \sin \beta \cdot \cos \beta-\sigma_{1} \cdot \sin \alpha \cdot \cos \alpha\right) \\
& \cdot \sqrt{\pi a},
\end{aligned}
$$

where $K_{\mathrm{I} 0}^{\mathrm{E}}$ and $K_{\mathrm{II} 0}^{\mathrm{E}}$ are the SIFs of Type I or Type II at the single crack tip under unloading conditions, respectively, and $a$ is the half length of the single crack. 


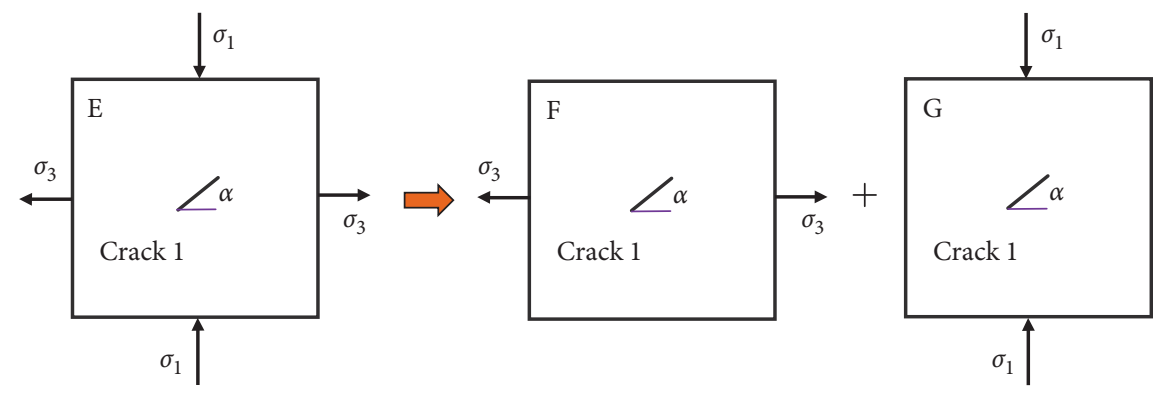

FIgURE 6: Superposition method of stress state of rock mass with single crack under unloading conditions.
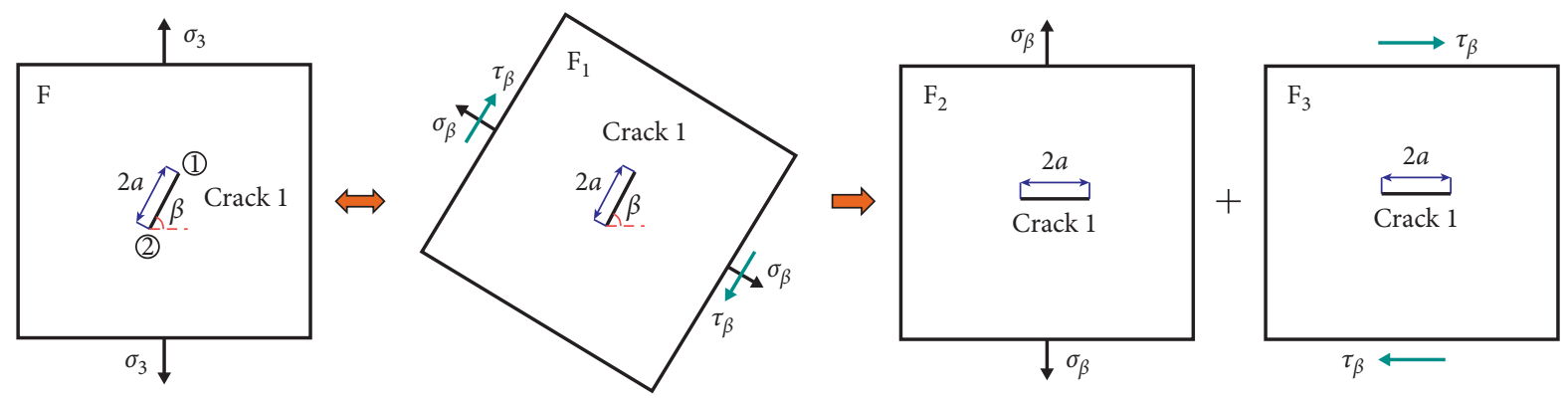

FIgURE 7: Equivalent sketch of stress state $(G)$ of rock mass under uniaxial tension.

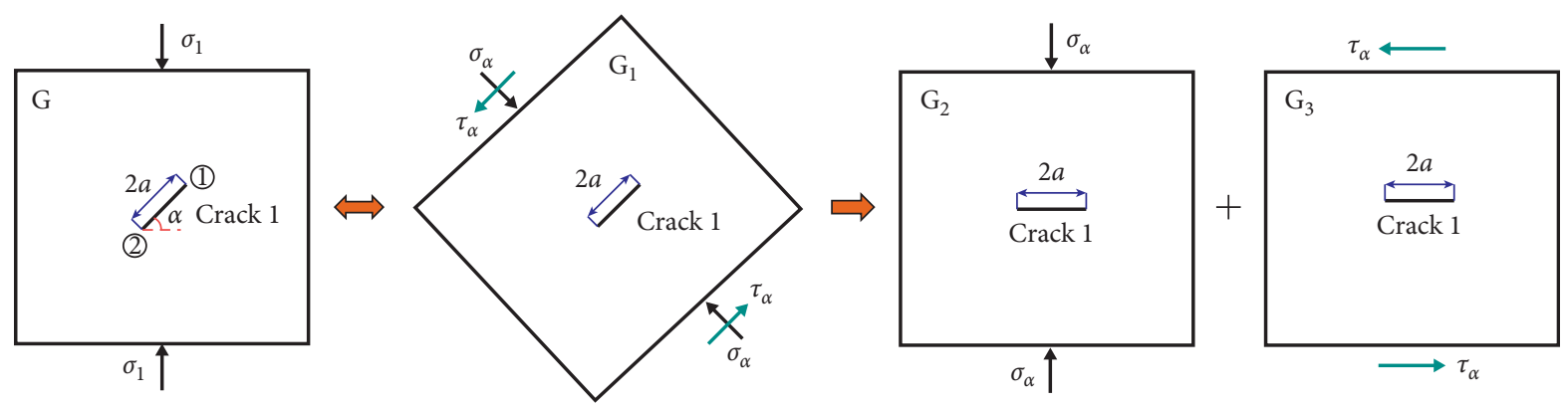

FiguRE 8: Equivalent sketch of stress state $(F)$ of rock mass under uniaxial compression.

\section{Parallel Offset Double Crack Propagation under Unloading Conditions}

The interactions among multiple cracks on the SIF at the crack tip may have reinforcing, null, or shielding effect $[25,26]$. In this paper, the ratio $\left(K^{\mathrm{A}} / K^{\mathrm{E}}\right)$ of the SIF at the crack tip in the stress state of the rock mass with double cracks under unloading conditions to that in the stress state of the rock mass with single crack under unloading conditions is defined as the interaction coefficient (IC). The IC reflects the effect of other cracks on the initiation and propagation of the crack tip being studied under unloading conditions. According to reference [27], when the center distance of two equal length cracks is equal to twice the crack length, the propagation of the two cracks is only related to their own geometric parameters. At this time, the interaction between the two cracks is small and negligible. According to reference [24], it can be found that the ratio of the SIF at the crack tip to the SIF in the presence of only a single crack is about 1.0. Therefore, when the increasing coefficient of stress intensity factor of a crack is about 1.0, it is considered that the existence of other cracks has no effect on the propagation of the crack. Therefore, the paper defines that when $K^{\mathrm{A}} / K^{\mathrm{E}}>1$, the crack falls into the reinforcing effect zone; when $K^{\mathrm{A}} / K^{\mathrm{E}}=1$, the crack is in the null effect zone; when $K^{\mathrm{A}} / K^{\mathrm{E}}<1$, the crack is in the shielding effect zone. The IC serves here as an evaluation index to discuss the interaction law of parallel offset double cracks:

$$
\begin{aligned}
\mathrm{IC}^{\mathrm{I}} & =\frac{K_{\mathrm{I}}^{\mathrm{A}}}{K_{\mathrm{I}}^{\mathrm{E}}}=\frac{F_{\mathrm{I}}^{\mathrm{C}_{2}} \cdot \sigma_{3} \cdot \cos ^{2} \beta}{\sigma_{3} \cdot \cos ^{2} \beta}=F_{\mathrm{I}}^{\mathrm{C}_{2}}, \\
\mathrm{IC}^{\mathrm{II}} & =\frac{K_{\mathrm{II}}^{\mathrm{A}}}{K_{\mathrm{II}}^{\mathrm{E}}}=\frac{\left(F_{\mathrm{II}}^{\mathrm{C}_{2}} \cdot \cos ^{2} \beta+F_{\mathrm{II}}^{\mathrm{C}_{3}} \cdot \sin \beta \cdot \cos \beta\right) \cdot \sigma_{3}-\left(F_{\mathrm{II}}^{\mathrm{D}_{2}} \cdot \cos ^{2} \alpha+F_{\mathrm{II}}^{\mathrm{D}_{3}} \cdot \sin \alpha \cdot \cos \alpha\right) \cdot \sigma_{1}}{\sigma_{3} \cdot \sin \beta \cdot \cos \beta-\sigma_{1} \cdot \sin \alpha \cdot \cos \alpha},
\end{aligned}
$$


where IC ${ }^{\mathrm{I}}$ and IC $\mathrm{II}^{\mathrm{II}}$ are ICs of Type I or Type II at the crack tip under unloading conditions.

3.1. Effect of Staggered Distance (h) between Cracks. Only the IC variations of Type I at the inner and outer tip of Crack 1 (position (i) and position (ii) in Figure 4) are discussed here due to space limitations. In order to simplify the calculation, let $\sigma_{1}=2 \mathrm{MPa}, \sigma_{3}=1 \mathrm{MPa}$, and $\alpha=\beta=45^{\circ}$. The calculated results and variation curves of the ICs of the tip of Crack 1 with the staggered distance ratio $(h / a)$ are shown in Table 1 and Figure 9.

3.2. Effect of Length of Rock Bridge (s) between Cracks. In order to simplify the calculation, let $\sigma_{1}=2 \mathrm{MPa}, \sigma_{3}=1 \mathrm{MPa}$, and $\alpha=\beta=45^{\circ}$. The calculated results and variation curves of the ICs of the tip of Crack 1 with the length of the rock bridge ratio $(s / a)$ are shown in Table 2 and Figure 10.

As shown in Figure 10(a), when the staggered distance is constant, the shielding effect of Type I on the tip of Crack 1 gradually weakens and transforms into reinforcing effect as the length of the rock bridge increases. The IC begins to decrease and gradually approaches 1.0 , that is, the reinforcing effect on the crack tip begins to weaken and gradually transforms into null effect. Again, the interaction at the tip of the crack is more severe when the cracks are closer together. As shown in Figure 10(b), when the staggered distance is small (Curves 1,2, and 3), the reinforcing effect on the outer tip of Crack 1 increases at first and then weakens and gradually transforms into null effect as the length of the rock bridge increases. When the staggered distance is large (Curves 4 and 5), the shielding effect of Type I on the outer tip of Crack 1 gradually weakens and transforms into reinforcing effect as the length of rock bridge increases; the reinforcing effect on the crack tip begins to weaken and ultimately transforms into null effect. The curves change to greater extent as the length of the rock bridge increases. Again, the interactions at the tip of the crack are more severe and more sensitive to distance when the length of the rock bridge between cracks is small.

3.3. Effect of Crack Inclination Angle ( $\alpha$ ). In order to simplify the calculation, let $\sigma_{1}=2 \mathrm{MPa}, \sigma_{3}=1 \mathrm{MPa}$, and $s=0$.The calculated results and variation curves of the ICs of the tip of Crack 1 with the crack inclination angle $(\alpha)$ are shown in Table 3 and Figure 11.

As shown in Figure 11, the ICs of Type I of the inner tip of Crack 1 remain unchanged as the crack inclination angle increases. The ICs of Type II decrease continuously, which indicates that the interaction strength (reinforcing or shielding effect) of Type I of the inner tip of Crack 1 is not affected by the crack inclination angle, while that of Type II increases with crack inclination angle. The shear-failure trend of the inner tip of the crack weakens gradually as the crack inclination angle $(\alpha)$ increases. When the length of the rock bridge is constant, a greater staggered distance results in smoother IC variation curves of Type II. A smaller staggered distance results in more intense changes in the ICs of Type II of the crack tip with inclination angle. The change is most severe when the angle $\alpha$ is around $60^{\circ}$. A smaller staggered distance between cracks makes the inner crack tip shearfailure more sensitive to variations in the crack inclination angle $(\alpha)$. The sensitivity is highest when the angle $\alpha$ is around $60^{\circ}$.

\section{Lateral Unloading Test of Rock-Like Specimens with Parallel Offset Double Cracks}

4.1. Specimen Preparation and Test Arrangement. Prefabricated crack-containing rock specimens, which are easily poured, form quickly, low in cost, and easy to analyze, were made of rock-like materials to verify the accuracy of the above theoretical analysis experimentally [28]. The rock-like material was made of cement mortar consisting 425 Portland cement, standard sand, and water in a cement: sand: water ratio of $1: 2.35: 0.5$. Under International Society of Rock Mechanics standards, the specimen was processed to $110 \mathrm{~mm} \times 110 \mathrm{~mm} \times 30 \mathrm{~mm}$ size including two nonpenetrating parallel cracks $0.5 \mathrm{~mm}$ in thickness prefabricated by two thin stainless steel sheets as shown in Figure 12.

The mechanical parameters of the intact cement mortar specimens, which are similar to those of sandstone [29], are shown in Table 4. Six groups of two-crack specimens were made to assess the effects of staggered distance $(h)$, length of rock bridge $(s)$, and inclination angle $(\alpha)$ of cracks on the interactions among cracks as they propagate. The geometric parameters of cracks in each group of specimens are listed in Table 5.

Based on the stress paths of the "key block" in the slope shown in Figure 1 before and after excavation, the lateral unloading test was run to simulate nonpenetrating intermittent joints in the slope excavation process as per plane strain variations (without considering the intermediate principal stress). The experimental device is an MS-500 triaxial impact rockburst test system independently developed by the State Key Laboratory for Geomechanics and Deep Underground Engineering of China University of Mining and Technology, Beijing. As shown in Figure 13, the loading system is three-direction independent. It can realize three-direction asynchronous loading and unloading as well as three-direction or any two-direction synchronous loading and unloading [30]. An SA-5 high-speed digital camera and stress-strain monitoring system were used to monitor the failure processes of the specimens and collect images during the tests.

4.2. Test Scheme. The test is a plane strain problem which was solved according to the following scheme:

(i) As shown in Figure 14(a), axial pressure and horizontal pressure were loaded to $1 \mathrm{MPa}$ at a rate of $0.004 \mathrm{~mm} / \mathrm{s}$ simultaneously under displacement loading control. The bidirectional displacement was kept constant.

(ii) Under the loading control mode, axial pressure and horizontal pressure were loaded to $15 \mathrm{MPa}$ at a rate 
TABLE 1: ICs varying with staggered distance ratio $(h / a)$.

\begin{tabular}{ccccccccc}
\hline & \multicolumn{4}{c}{ Inner tip (Crack 1) } & \multicolumn{3}{c}{ Outer tip (Crack 1) } \\
& $s / a=0.8$ & $s / a=0.0$ & $s / a=-1.0$ & $s / a=-1.5$ & $s / a=0.8$ & $s / a=0.0$ & $s / a=-1.0 \quad 1.0$ & $s / a=-1.5$ \\
\hline 0.1 & 1.230 & 2.052 & 0.187 & 0.073 & 1.080 & 1.252 & 1.256 \\
0.2 & 1.191 & 1.544 & 0.350 & 0.240 & 1.071 & 1.211 & 1.206 \\
0.5 & 1.160 & 1.128 & 0.614 & 0.558 & 1.067 & 1.132 & 1.096 \\
0.8 & 1.086 & 1.008 & 0.750 & 0.725 & 1.069 & 1.085 & 1.012 \\
1.0 & 1.047 & 0.961 & 0.808 & 0.783 & 1.055 & 1.054 & 0.985 \\
\hline
\end{tabular}

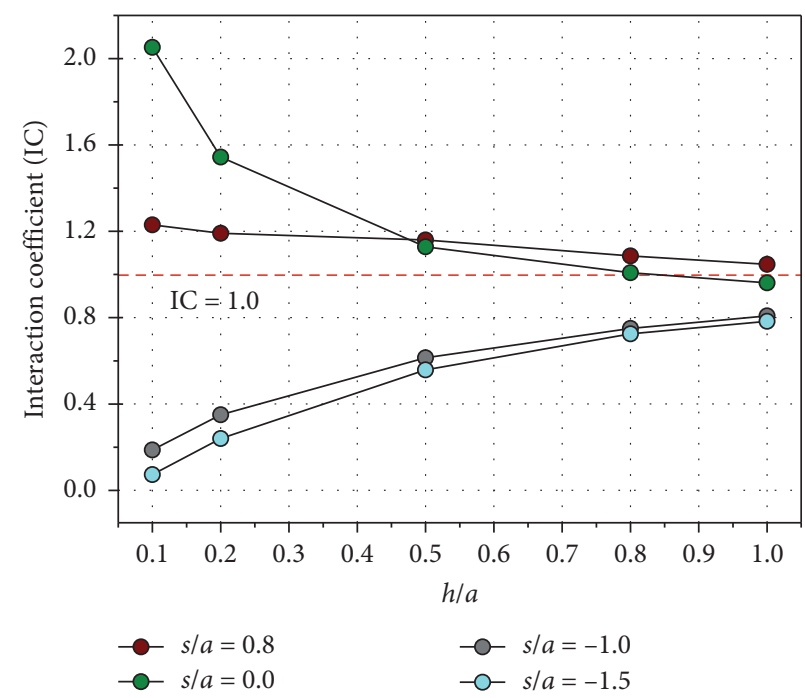

(a)

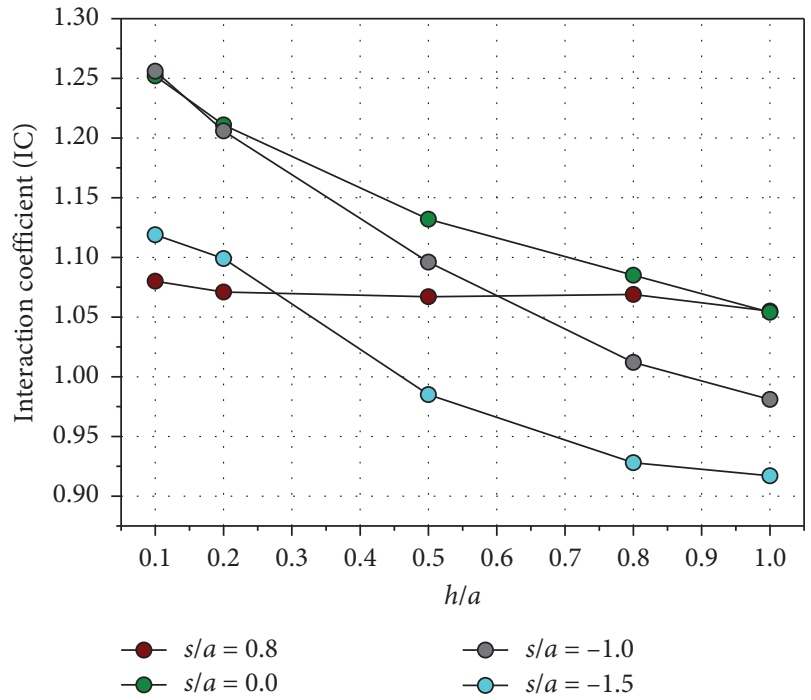

(b)

FIGURE 9: IC variations with staggered distance ratio under unloading conditions. (a) Inner tip (Crack 1). (b) Outer tip (Crack 1).

TABLE 2: ICs varying with length ratio of rock bridge $(s / a)$.

\begin{tabular}{|c|c|c|c|c|c|c|c|c|c|c|}
\hline \multirow{2}{*}{$s / a$} & \multicolumn{5}{|c|}{ Inner tip (Crack 1) } & \multicolumn{5}{|c|}{ Outer tip (Crack 1) } \\
\hline & $h / a=0.1$ & $h / a=0.2$ & $h / a=0.5$ & $h / a=0.8$ & $h / a=1.0$ & $h / a=0.1$ & $h / a=0.2$ & $h / a=0.5$ & $h / a=0.8$ & $h / a=1.0$ \\
\hline-1.5 & 0.073 & 0.240 & 0.558 & 0.725 & 0.783 & 1.119 & 1.099 & 1.022 & 0.928 & 0.917 \\
\hline-1 & 0.187 & 0.350 & 0.614 & 0.750 & 0.808 & 1.256 & 1.206 & 1.096 & 1.012 & 0.981 \\
\hline 0 & 2.052 & 1.544 & 1.128 & 1.008 & 0.961 & 1.252 & 1.211 & 1.132 & 1.085 & 1.054 \\
\hline 0.8 & 1.230 & 1.191 & 1.160 & 1.086 & 1.047 & 1.091 & 1.095 & 1.087 & 1.074 & 1.057 \\
\hline 1 & 1.156 & 1.145 & 1.137 & 1.087 & 1.056 & 1.080 & 1.071 & 1.067 & 1.069 & 1.055 \\
\hline 1.5 & 1.070 & 1.071 & 1.095 & 1.076 & 1.056 & 1.048 & 1.045 & 1.043 & 1.041 & 1.039 \\
\hline
\end{tabular}

of $0.5 \mathrm{kN} / \mathrm{s}$ simultaneously $\left(0 \leq t<t_{1}\right)$ as the horizontal pressure reached the predetermined value. The bidirectional load was held for $1 \mathrm{~min}$ $\left(t_{1} \leq t<t_{2}\right)$.

(iii) The horizontal pressure was kept constant as axial pressure was loaded to $20 \mathrm{MPa}$ at a rate of $0.5 \mathrm{kN} / \mathrm{s}$ under loading control $\left(t_{2} \leq t<t_{3}\right)$ as the axial pressure reached the predetermined value. The bidirectional load was held for $1 \mathrm{~min}\left(t_{3} \leq t<t_{4}\right)$.

(iv) Finally, as shown in Figure 14(b), the axial pressure was increased at a rate of $0.5 \mathrm{kN} / \mathrm{s}$ under the loading control mode and horizontal pressure was unloaded at a rate of $0.5 \mathrm{kN} / \mathrm{s}$ until the specimen was destroyed $\left(t_{4} \leq t<t_{5}\right)$.

\subsection{Test Result Analysis}

4.3.1. Crack Propagation. Due to space constraints, only the crack propagation processes of Specimens 1, 3, 4, and 6 are given here (Figures 15-18).

(1) Effect of the Staggered Distance (h) between Cracks. As shown in Figures 15 and 16, the length of rock bridges of Specimen 1 and Specimen 3 are equal at $-12 \mathrm{~mm}$; however, the staggered distances are $6 \mathrm{~mm}$ and $24 \mathrm{~mm}$, respectively. As shown in Figure 15, with the continuous lateral unloading of $\sigma_{3}$, the outer tip of the main crack in Model 1 initiates a wing crack first because it is outside the shielding effect zone of the secondary crack and is less affected by the secondary crack. The inner tip of the main crack and the 


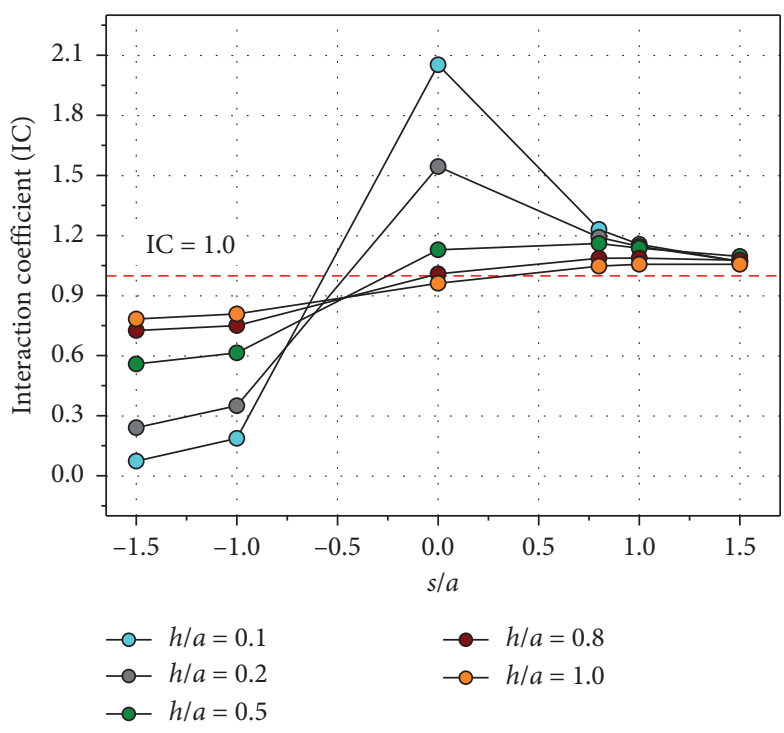

(a)

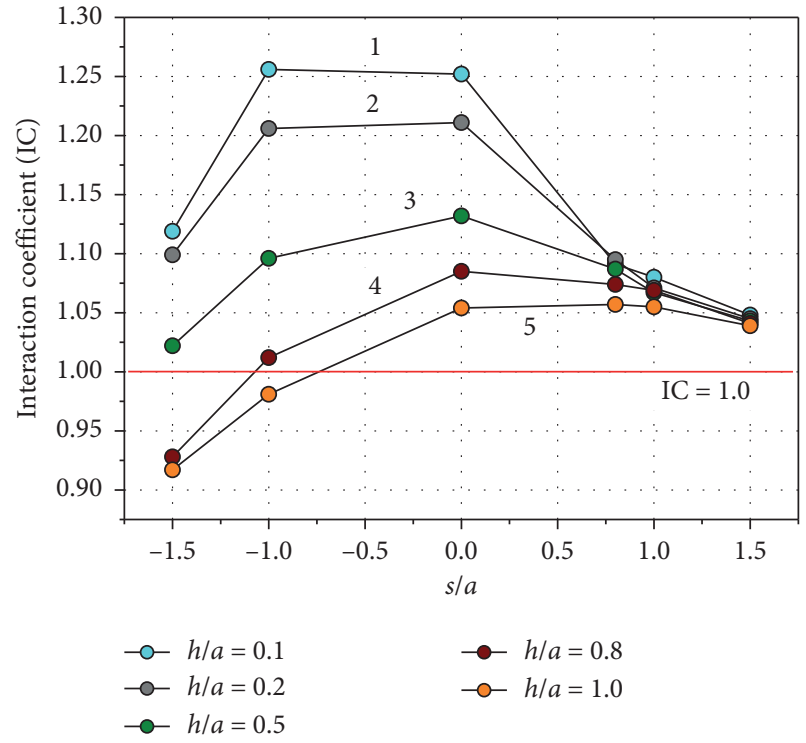

(b)

FIgure 10: IC variations with length ratio of the rock bridge under unloading conditions. (a) Type I. (b) Type II.

TABLE 3: ICs varying with crack inclination angle $(\alpha)$.

\begin{tabular}{cccccc}
\hline$\alpha$ & & Type I & & \multicolumn{2}{c}{ Type II } \\
$h / a=0.5$ & $h / a=1.0$ \\
\hline $15^{\circ}$ & $h / a=0.2$ & $h / a=0.5$ & $h / a=1.0$ & $h / a=0.2$ & 0.940 \\
$30^{\circ}$ & 1.539 & 1.128 & 0.958 & 0.894 & 0.878 \\
$45^{\circ}$ & 1.539 & 1.128 & 0.958 & 0.824 & 0.804 \\
$60^{\circ}$ & 1.539 & 1.128 & 0.958 & 0.676 & 0.673 \\
$75^{\circ}$ & 1.539 & 1.128 & 0.958 & 0.516 & 0.047 \\
\hline
\end{tabular}

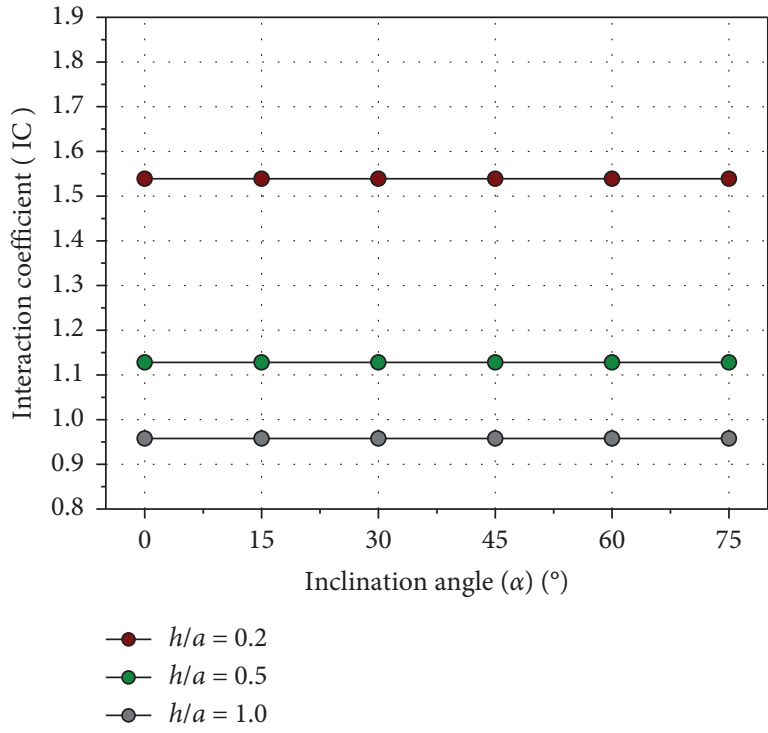

(a)

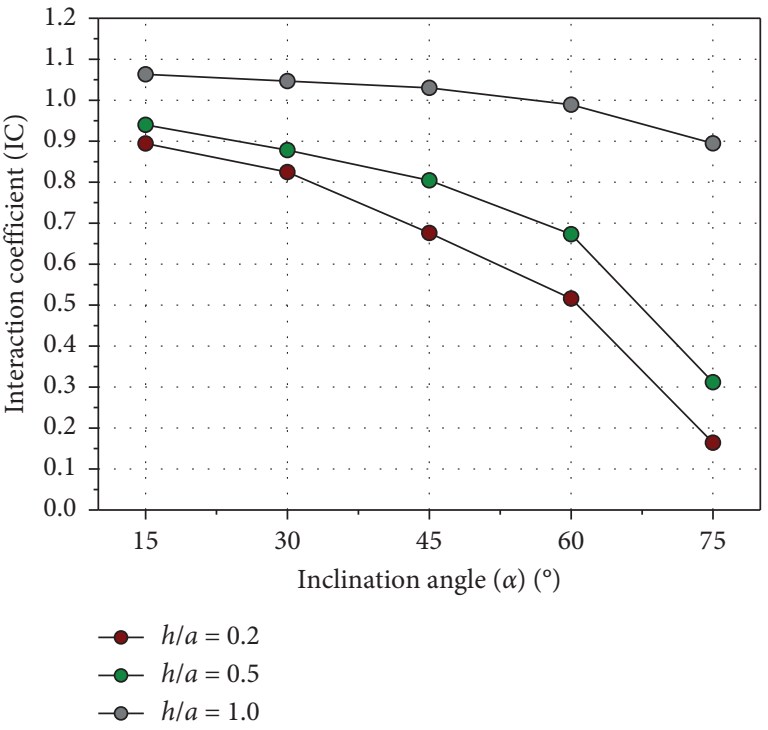

(b)

FIgURE 11: IC variations with crack inclination angle under unloading conditions. (a) Type I. (b) Type II. 


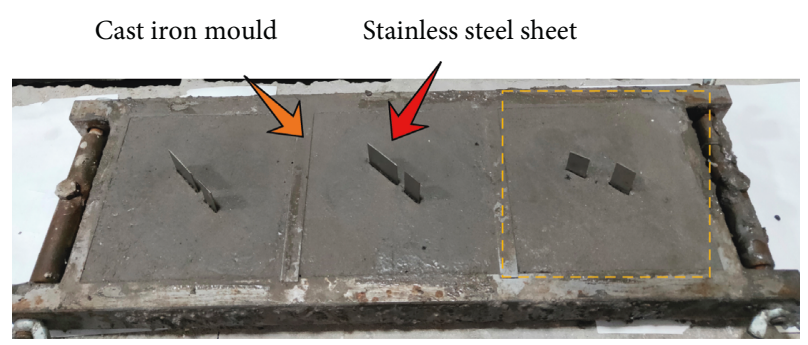

(a)

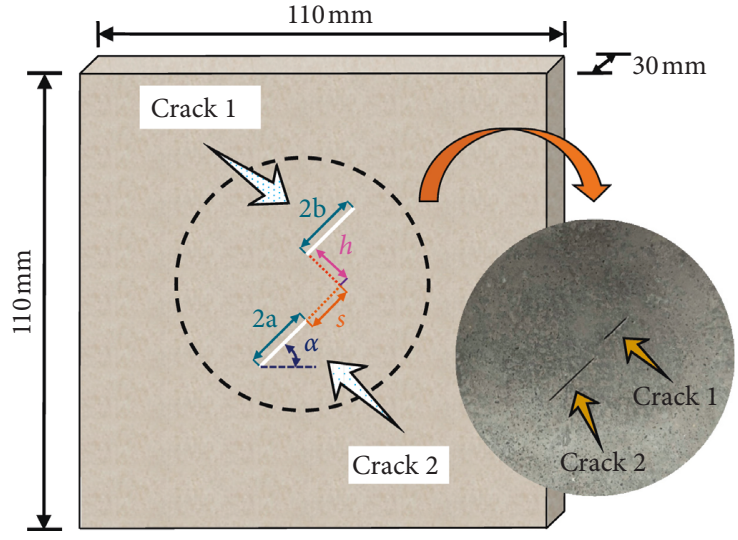

(b)

Figure 12: Sketch diagram of specimen dimensions.

TABLE 4: Mechanical properties of sandstone and specimens.

\begin{tabular}{lcccc}
\hline Materials & Density $\left(\mathrm{kg} / \mathrm{m}^{3}\right)$ & Elastic modulus $(\mathrm{GPa})$ & Uniaxial compressive strength $(\mathrm{MPa})$ & Poisson's ratio \\
\hline Sandstone & $10 \sim 100$ & $2000 \sim 2600$ & $4 \sim 25$ & $0.1 \sim 0.3$ \\
Model & 2350 & 15.2 & 55 & 0.15 \\
\hline
\end{tabular}

TABLE 5: Geometric parameters of cracks in specimens.

\begin{tabular}{lccccc}
\hline $\begin{array}{l}\text { Specimen } \\
\text { number }\end{array}$ & $\begin{array}{c}\text { Incline angle } \\
(\alpha)\left(^{\circ}\right)\end{array}$ & $\begin{array}{c}\text { Length of Crack 1 }(2 a) \\
(\mathrm{mm})\end{array}$ & $\begin{array}{c}\text { Length of Crack 2 }(2 b) \\
(\mathrm{mm})\end{array}$ & $\begin{array}{c}\text { Length of rock bridge }(\mathrm{s}) \\
(\mathrm{mm})\end{array}$ & $\begin{array}{c}\text { Staggered distance }(\mathrm{h}) \\
(\mathrm{mm})\end{array}$ \\
\hline 1 & 45 & 12 & 24 & -12 & 6 \\
2 & 45 & 12 & 24 & -12 & 12 \\
3 & 45 & 12 & 24 & -12 & 24 \\
4 & 45 & 12 & 24 & 12 & 6 \\
5 & 30 & 12 & 24 & 12 & 6 \\
6 & 75 & 12 & 24 & 12 & 6 \\
\hline
\end{tabular}

When $s$ is negative, it indicates that there is an overlap between the cracks.

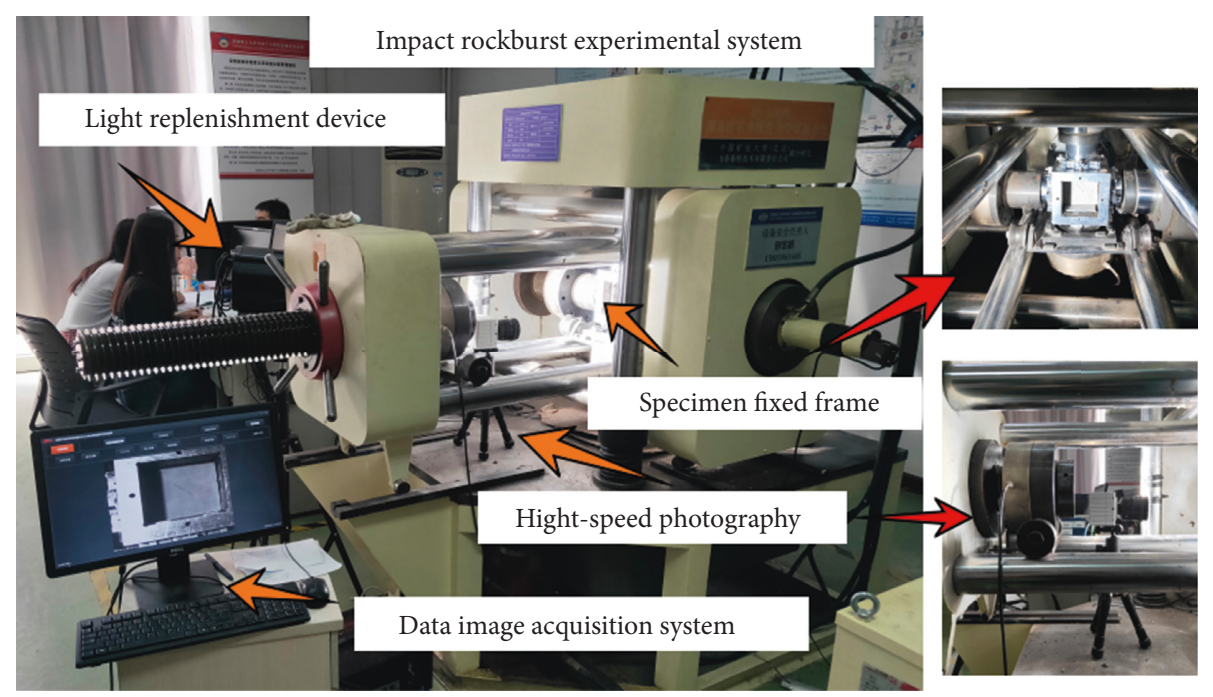

Figure 13: Experimental device. 

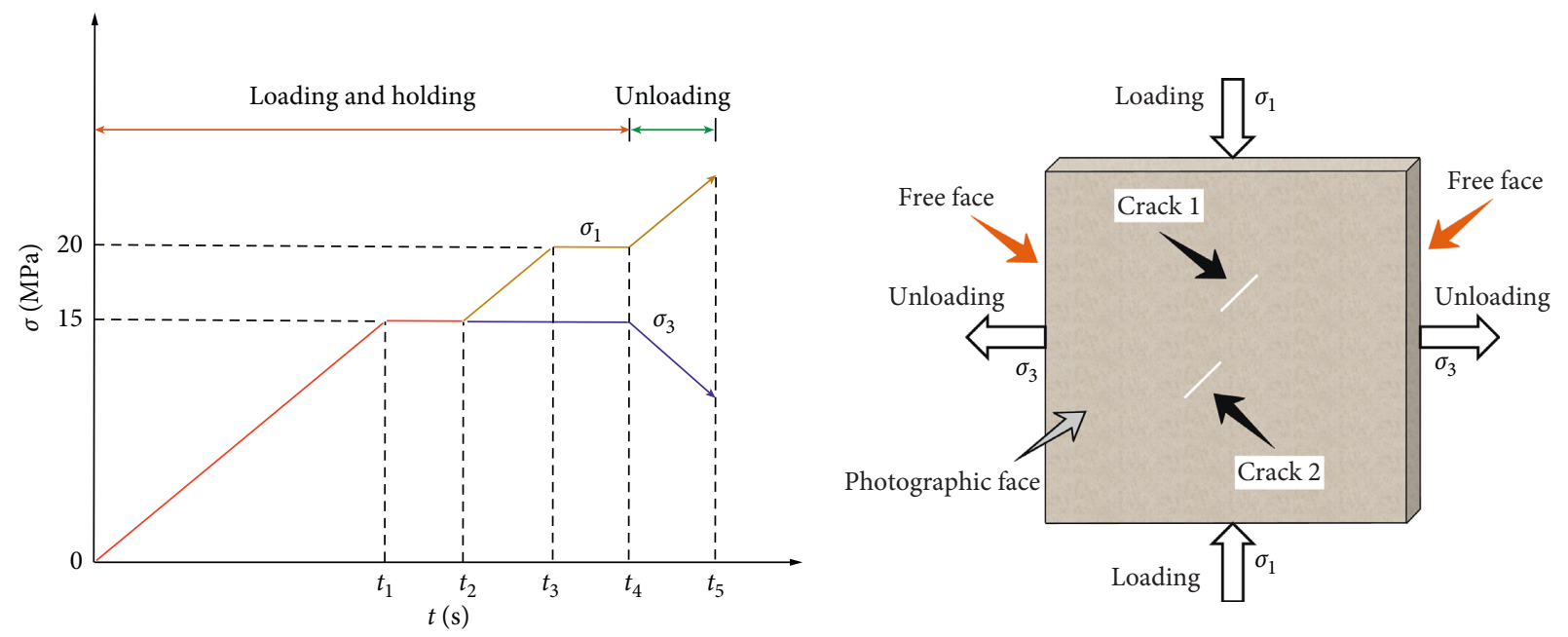

FIGURE 14: Sketch of the experimental stress path.
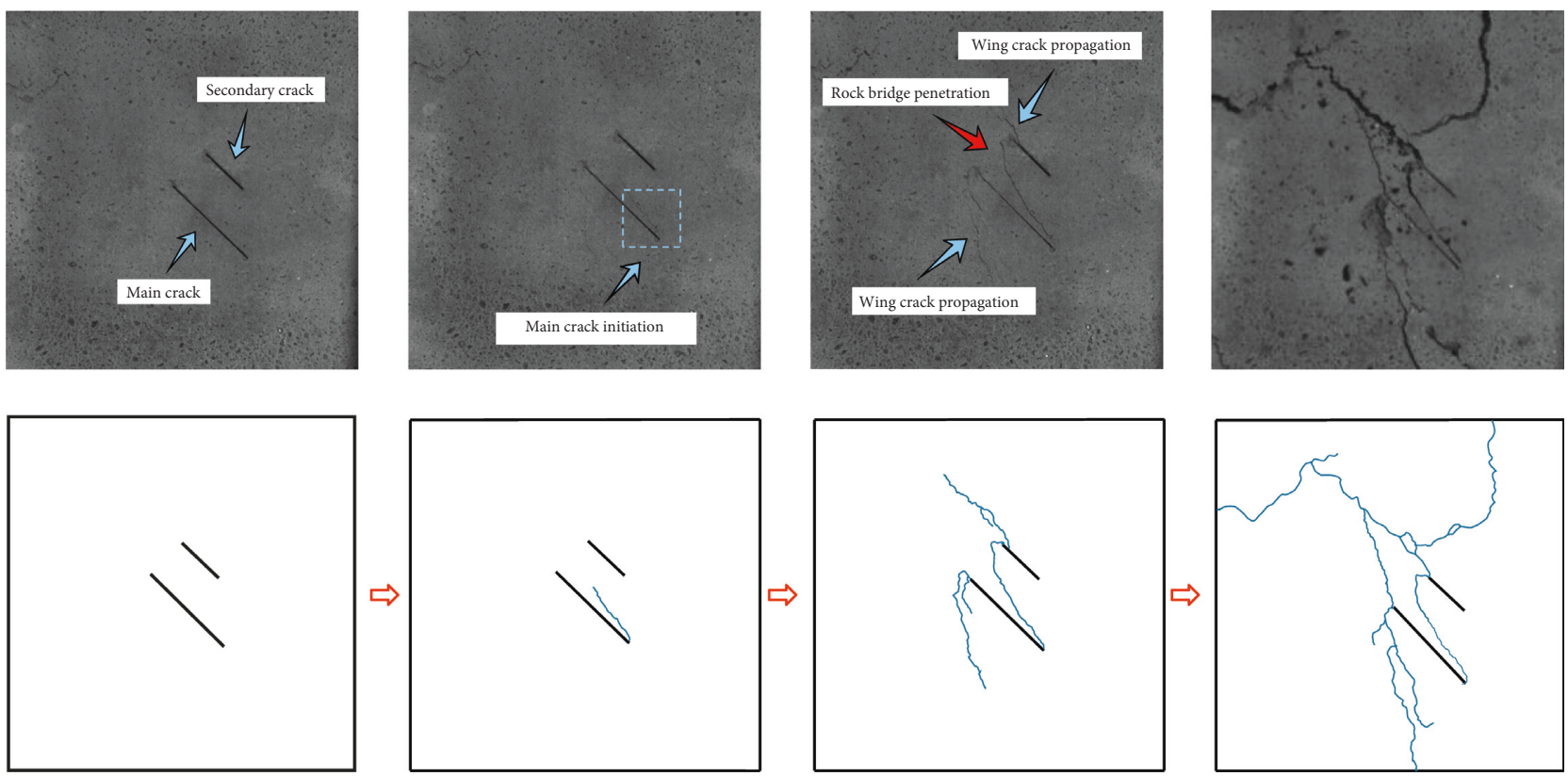

FIGURE 15: Crack propagation process of Specimen 1.

outer tip of the secondary crack then propagate until crack coalescence as unloading progresses, but the inner tip of the secondary crack within the shielding effect zone of the main crack does not crack during this process at all. The shielding effect of the main crack on the inner tip of the secondary crack is stronger than that on the outer tip of the secondary crack.

The staggered distance between cracks in Specimen 3 is $18 \mathrm{~mm}$ greater than that of Specimen 1. The inner tip of the secondary crack in Specimen 3 initiates the wing crack during the unloading process. The shielding effect between cracks is weakened in this specimen due to the increase of staggered distance between cracks. The staggered distance between cracks is an important factor in crack initiation and propagation. The shielding effect between cracks is weaker when staggered distance is larger and finally transforms into null effect, which is consistent with the theoretical results (Section 3.1).
(2) Effect of the Length of Rock Bridge (s) between Cracks. As shown in Figures 15 and 17, the staggered distances of Specimen 1 and Specimen 4 are both $6 \mathrm{~mm}$ and the length of rock bridges are both $-12 \mathrm{~mm}$. The length of rock bridge between cracks in Specimen 4 is $24 \mathrm{~mm}$ greater than that in Specimen 1. As shown in Figure 17, with the continuous lateral unloading of $\sigma_{3}$, the outer tip of the secondary crack in Specimen 3 initiates the wing crack during unloading. The inner tips of the main crack and secondary crack then propagate until the failure of the specimen as the shielding effect between cracks disappears and transforms into reinforcing effect with increase in the length of the rock bridge between cracks. The inner tip of the secondary crack in Specimen 4 is connected to the shear crack formed by the tip of the main crack during the unloading process, while the inner tip of the secondary crack in Specimen 1 does not 

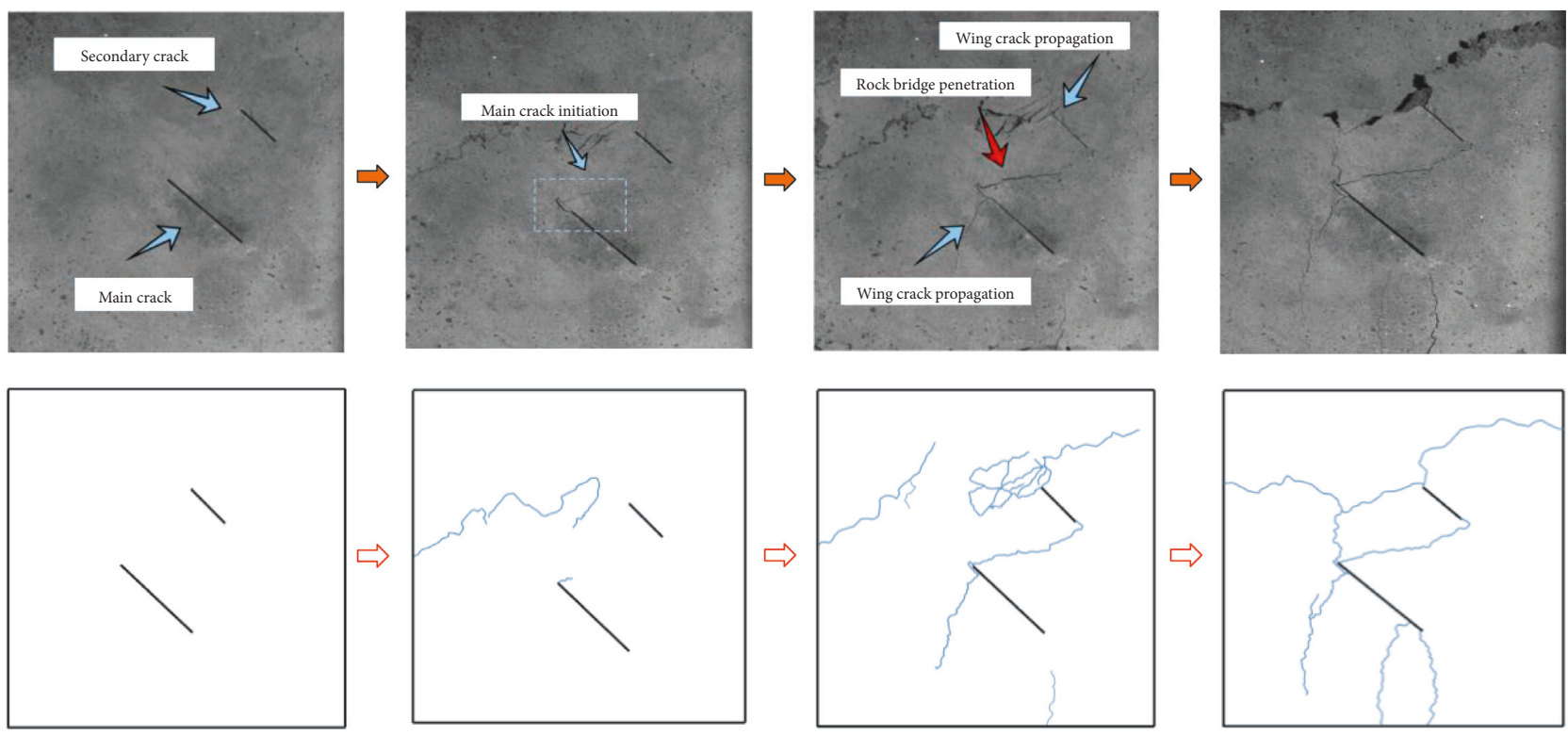

FIGURE 16: Crack propagation process of Specimen 3.
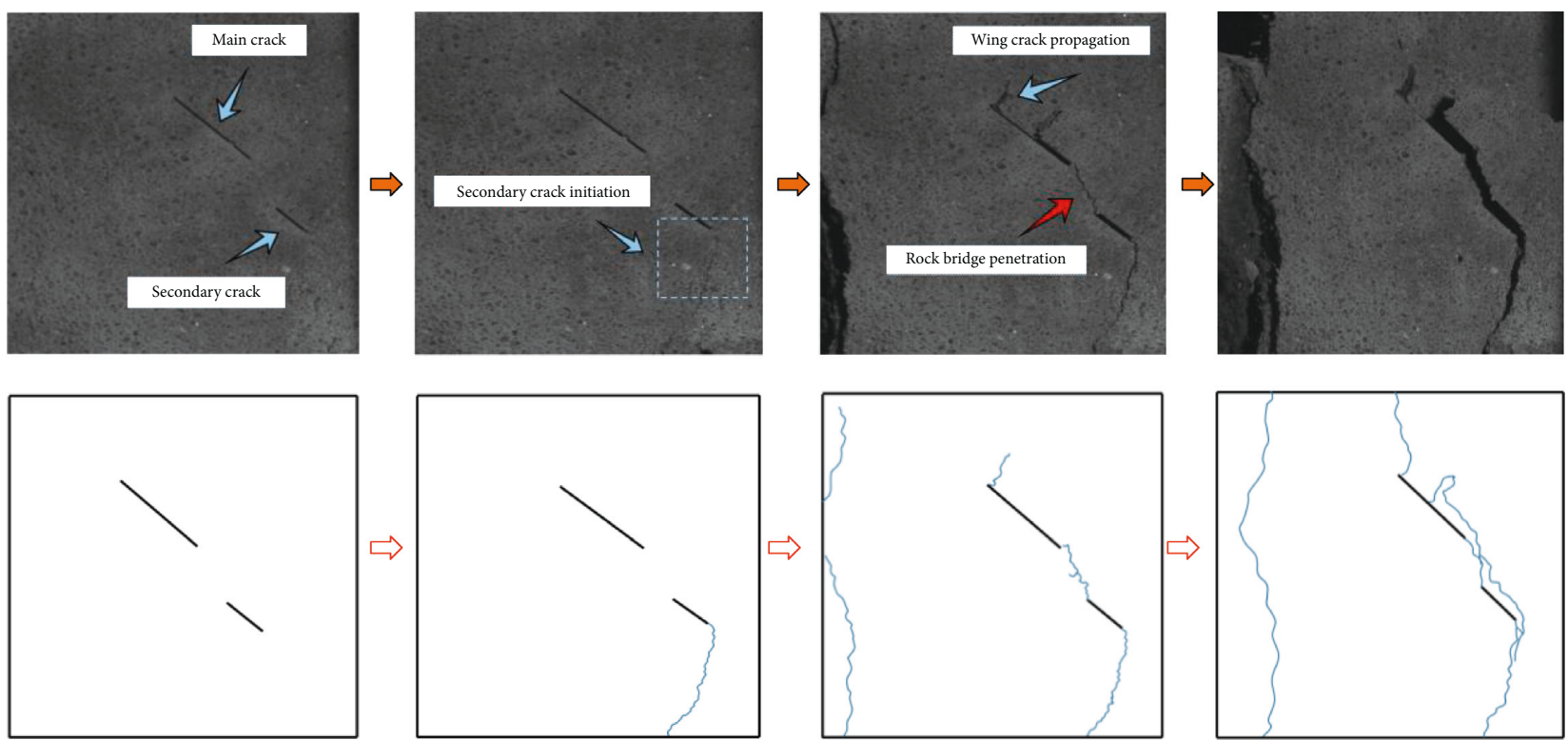

FIGURE 17: Crack propagation process of Specimen 4.

propagate during unloading. When the length of the rock bridge of cracks is negative (i.e., the cracks overlap), the cracks shield each other. As the length of the rock bridge increases, the interaction between cracks gradually changes from shielding to reinforcing. The reinforcing effect eventually becomes null. This is consistent with the theoretical results (Section 3.2).

(3) Effect of the Crack Inclination Angle ( $\alpha$ ). As shown in Figures 17 and 18, the horizontal and staggered distances of Specimens 4 and 6 are equal while the crack inclination angles $(\alpha)$ are $45^{\circ}$ and $75^{\circ}$, respectively. With the continuous lateral unloading of $\sigma_{3}$, the inner tip of the secondary crack in Specimen 6 initiates a wing crack which spreads in a direction almost perpendicular to the original crack. There is no shear penetration of the rock bridge when the specimen is finally destroyed. The shielding effect of Type II on the inner tips of cracks is gradually enhanced as the inclination angle increases, and the shear failure trend of the tips is gradually weakened, which is consistent with the theoretical analysis (Section 3.3).

4.3.2. Analysis of Crack Initiation Load. The axial loaddisplacement curves of Specimens 1, 3, 4, and 6 are shown in Figure 17.

As shown in Figure 19 and Table 6, the axial peak load and initiation load of Specimen 4 are smaller than those of other specimens. The main reason is that the tips of the two cracks in Specimen 4 are all in the reinforcing effect zone of each other compared with other specimens, and the tips are 

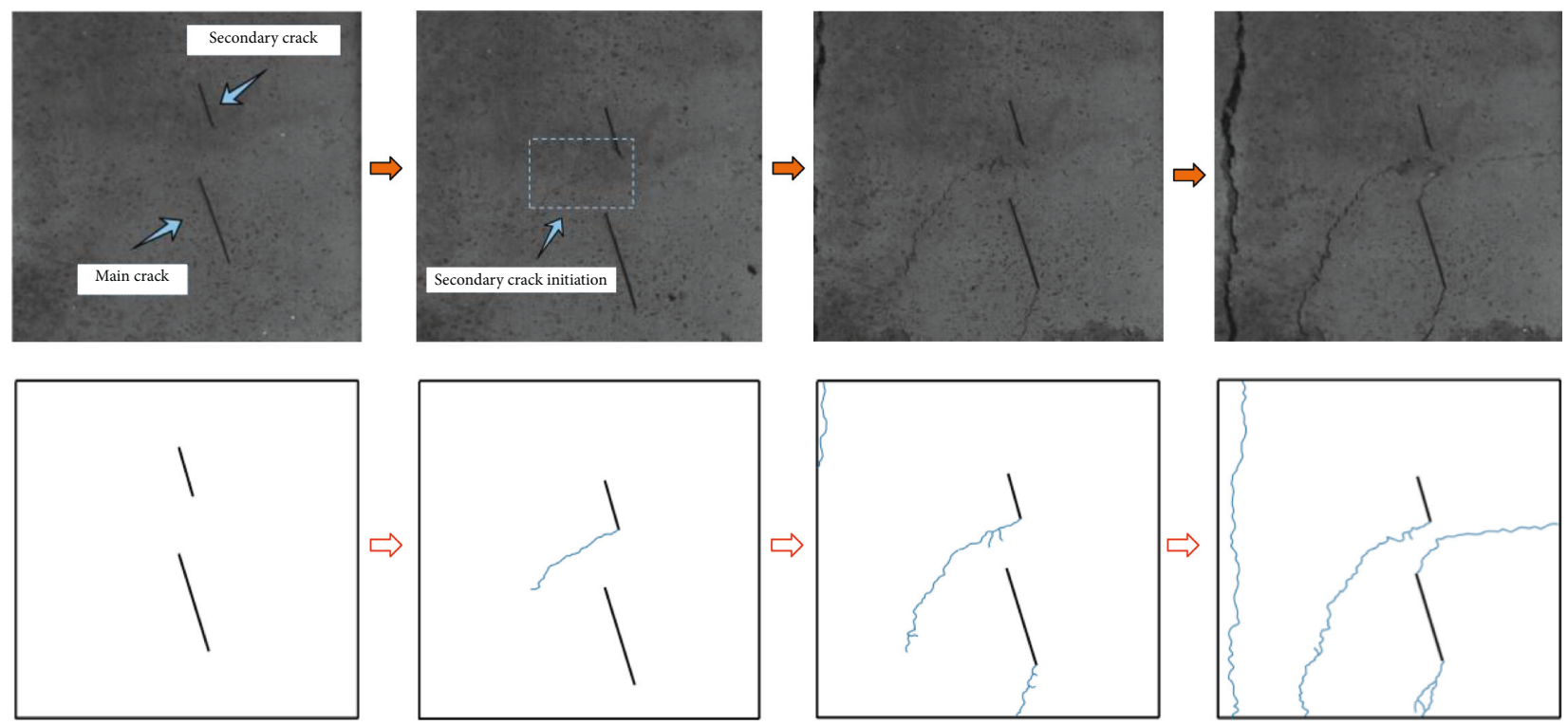

Figure 18: Crack propagation process of Specimen 6.

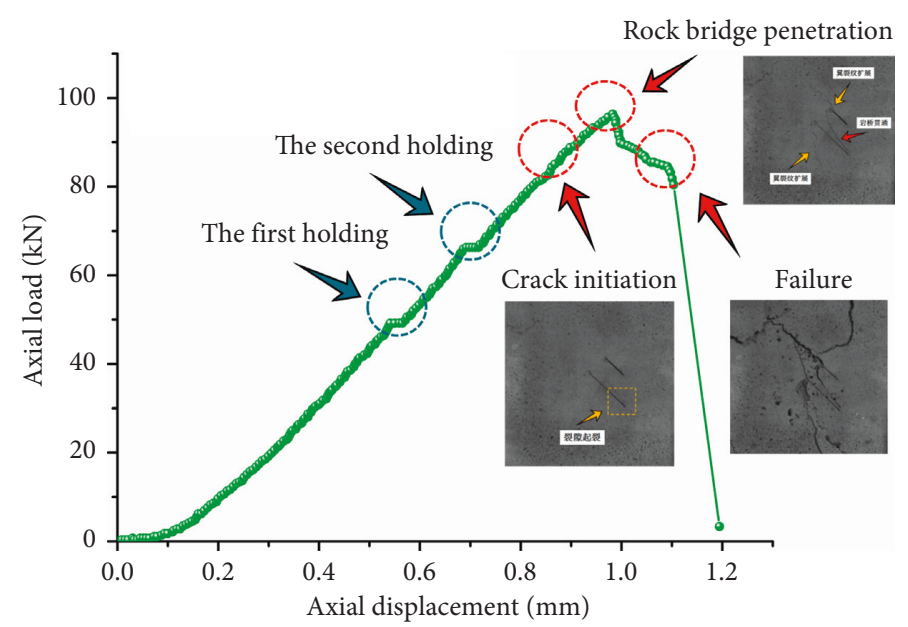

$\longrightarrow$ Axial load-displacement curve

(a)

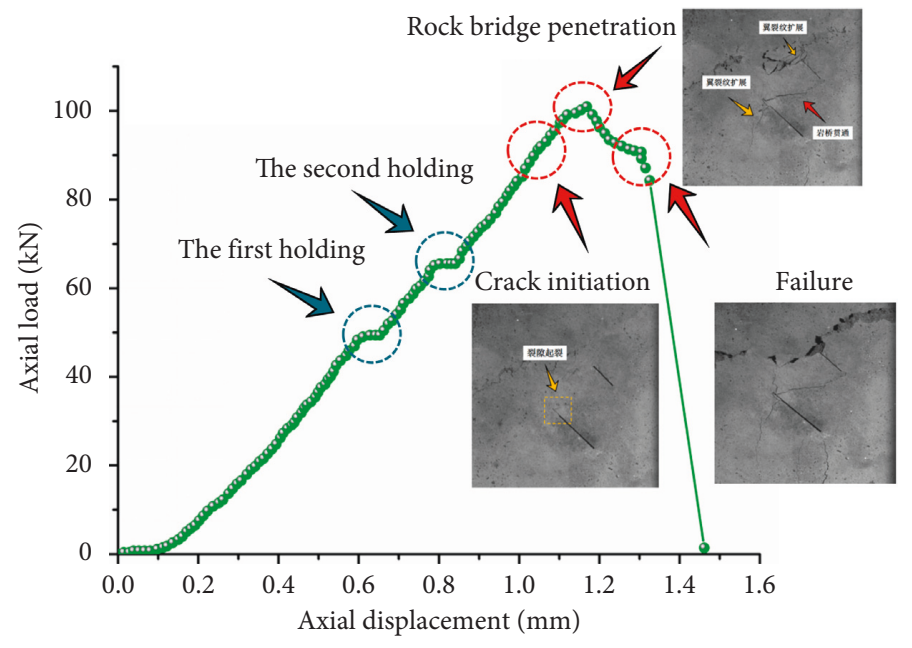

$\longrightarrow$ Axial load-displacement curve

(b)

FIgURE 19: Continued. 


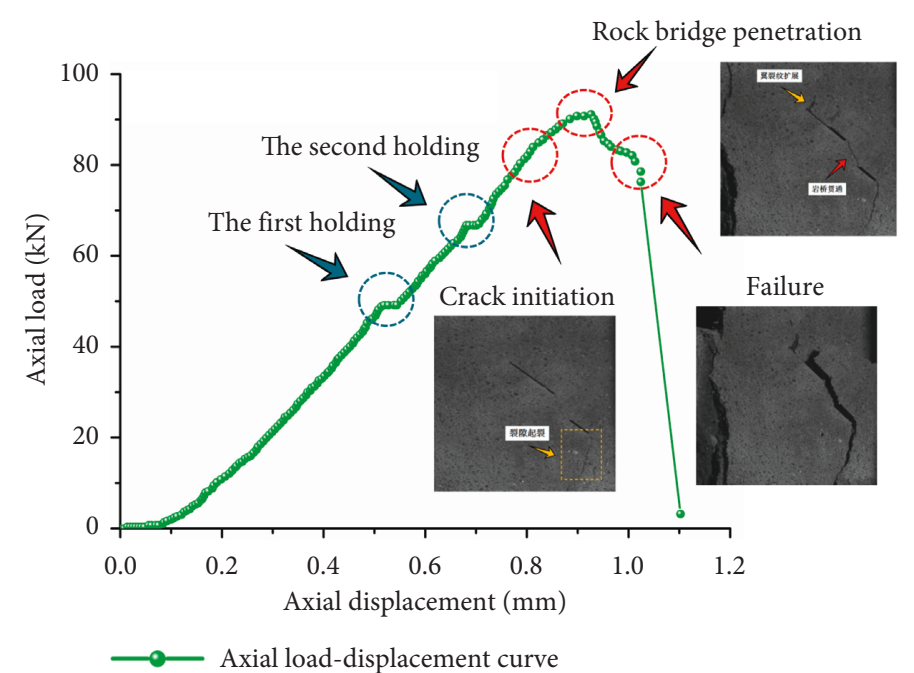

(c)

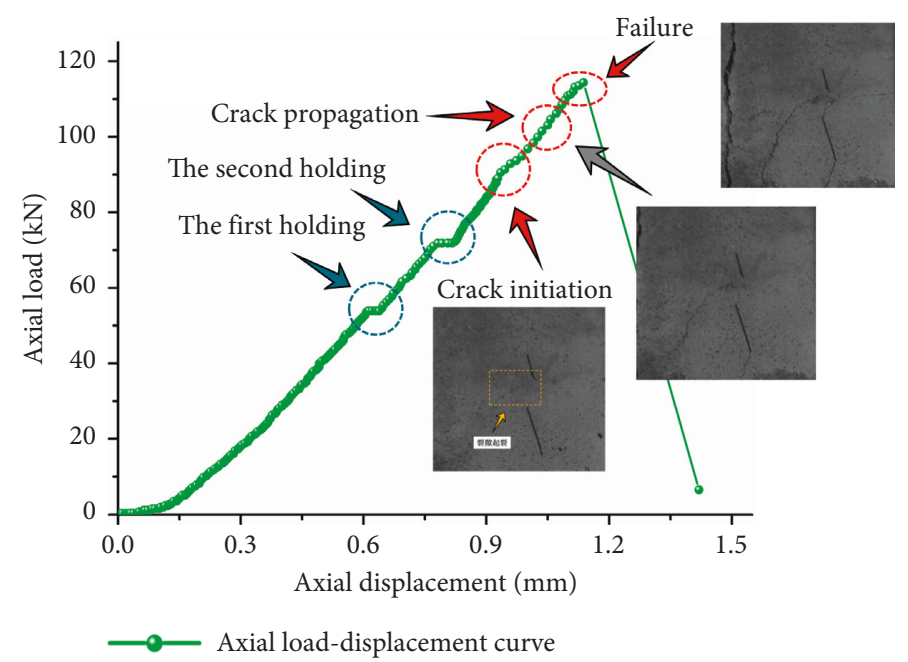

(d)

FIgURe 19: Axial load-displacement curves of specimens. (a) Specimen 1. (b) Specimen 3. (c) Specimen 4. (d) Specimen 6.

TABLE 6: Geometric parameters of cracks in specimens.

\begin{tabular}{lcc}
\hline Specimen number & Peak load $(\mathrm{kN})$ & Initiation load $(\mathrm{kN})$ \\
\hline 1 & 96.34 & 85.17 \\
3 & 100.94 & 92.13 \\
4 & 91.11 & 83.52 \\
6 & 114.38 & 94.28 \\
\hline
\end{tabular}

more likely to crack. It shows that the length of the rock bridge between cracks, the distance between cracks, and the angle of cracks have important influence on the initiation of cracks and the failure of specimens. In effect, the length of the rock bridge, staggered distance, and inclination angle all markedly affect crack initiation and specimen failure. When the length of the rock bridge between the cracks is constant, that is, $s=|a|$ ( $a$ is length of the rock bridge value and $a \geq 0$ ), the peak load and initiation load of the specimen when the length of the rock bridge is negative $(s=-a$, that is, cracks overlap) are greater than those when the length of the rock bridge is positive $(s=a$, no overlap between cracks). When the length of the rock bridge between the cracks is negative, the crack tip falls into the shielding effect zone and the wing crack at the tip is unlikely to propagate. As the staggered distance between cracks or the inclination angle of cracks increases, the peak load and initiation load also increase.

\section{Numerical Simulation Analysis}

5.1. Numerical Calculation Model. To further validate the above theoretical and experimental analyses, numerical simulation of the four groups of specimen models (Figure 20) under biaxial loading and lateral unloading was carried out in $\operatorname{RFPA}^{2 \mathrm{D}}[31,32]$ software. The size of the models is $110 \mathrm{~mm} \times 110 \mathrm{~mm}$, and there are $330 \times 330$ grid elements in total. The Mohr-Coulomb yield criterion was adopted for the plane strain calculation. To prevent boundary effect from influencing the crack failure, cracks were arranged in the middle of the models. The calculation parameters are listed in Table 7. 


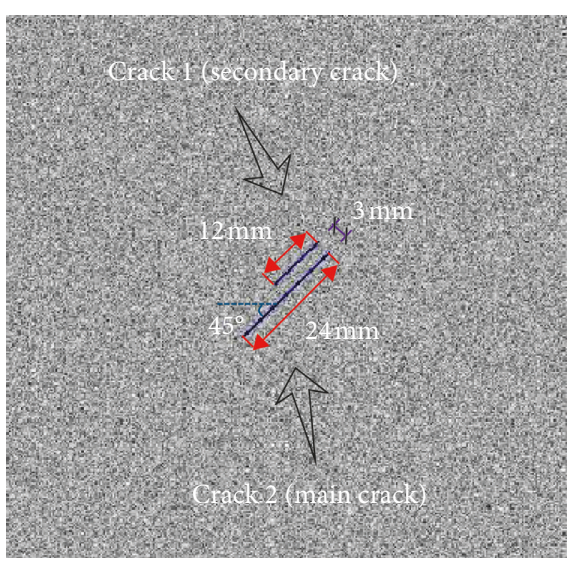

(a)

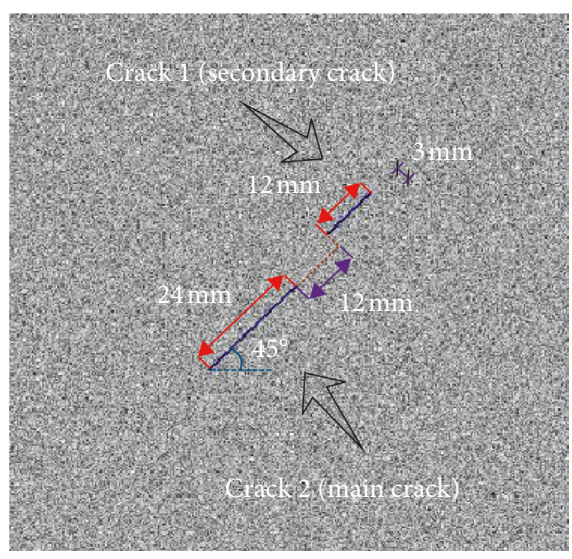

(c)

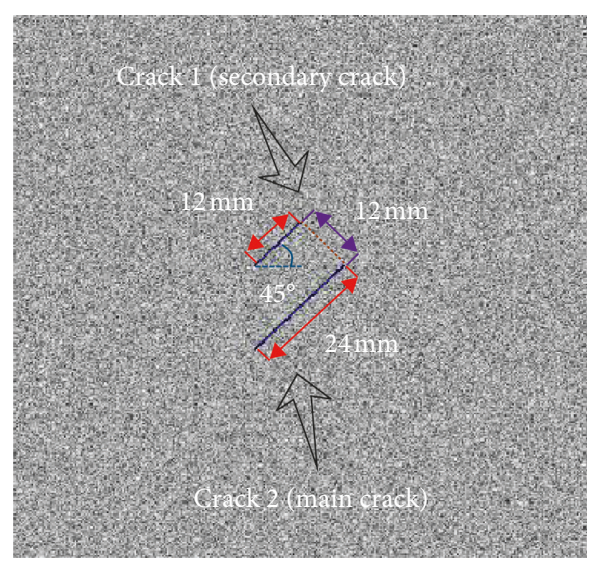

(b)

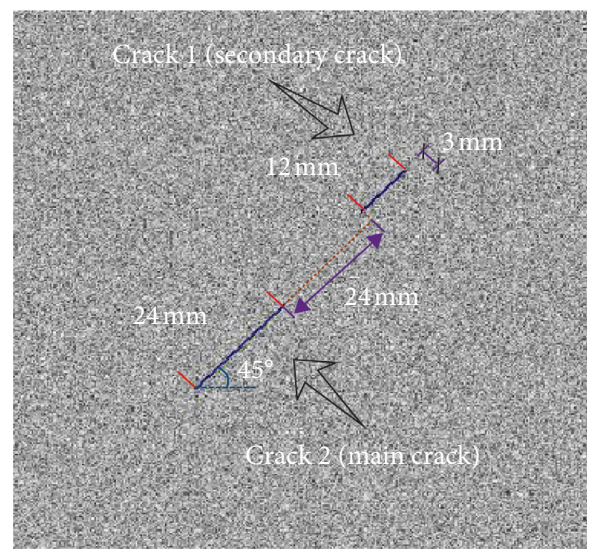

(d)

Figure 20: Numerical models. (a) Model 1. (b) Model 2. (c) Model 3. (d) Model 4.

TABLE 7: Numerical model parameters.

\begin{tabular}{|c|c|c|c|c|c|c|c|c|c|}
\hline $\begin{array}{l}\text { Elastic } \\
\text { modulus } \\
(\mathrm{GPa}) \\
\end{array}$ & $\begin{array}{c}\text { Density } \\
\left(\mathrm{kg} \cdot \mathrm{m}^{-3}\right)\end{array}$ & $\begin{array}{l}\text { Internal } \\
\text { friction } \\
\text { angle }\left(^{\circ}\right)\end{array}$ & $\begin{array}{l}\text { Poisson's } \\
\text { ratio }\end{array}$ & $\begin{array}{c}\text { Average } \\
\text { compressive } \\
\text { strength }(\mathrm{MPa})\end{array}$ & $\begin{array}{c}\text { Compression } \\
\text { coefficient }\end{array}$ & $\begin{array}{c}\text { Tensile } \\
\text { coefficient }\end{array}$ & $\begin{array}{c}\text { Homogeneity } \\
\text { coefficient }\end{array}$ & $\begin{array}{c}\text { Residual } \\
\text { strength } \\
(\%)\end{array}$ & $\begin{array}{l}\text { Residual } \\
\text { Poisson's } \\
\text { ratio (\%) }\end{array}$ \\
\hline 15.2 & 2350 & 30 & 0.15 & 53 & 200 & 1.5 & 5 & 0.1 & 1.1 \\
\hline
\end{tabular}

In the simulation, biaxial loading and lateral unloading were controlled by stress. Axial pressure and confining pressure were first applied to the predetermined values $\sigma_{1}^{0}=$ $20 \mathrm{MPa}$ and $\sigma_{3}^{0}=15 \mathrm{MPa}$ at rates of $2 \mathrm{MPa} /$ step and $1.5 \mathrm{MPa} / \mathrm{step}$, respectively. The axial pressure was held constant, and the confining pressure removed at a rate of $0.5 \mathrm{MPa} /$ step until the models were destroyed. Finally, the initiation and propagation laws of the internal cracks under the action of lateral unloading were analyzed by intercepting the maximum shear stress cloud diagram and acoustic emission diagram of different calculation steps in the model failure process. In the figures below, the stress magnitude is represented by the brightness of the element.

5.2. Result Analysis. The initiation and propagation processes of cracks in Models 1-4 under lateral unloading are shown in Figures 21-24.
As shown in Figures 21 and 22, the inner tip of the secondary crack in Model 2 initiates a wing crack during the continuous lateral unloading of $\sigma_{3}$, though the inner tip of the secondary crack in Model 1 does not crack during the whole process. This phenomenon is similar to the crack propagation processes of Specimens 1 and 3 (Figures 15 and 16) in the lateral unloading test. The inner tip of the secondary crack in Specimen 1 does not crack during the whole process, however, that in Specimen 3 cracks during the test. As shown in Figures 21, 23, and 24, the inner tip of the secondary crack in Model 3 initiates a wing crack during continuous lateral unloading of $\sigma_{3}$ which connects to the wing crack formed at the inner tip of the main crack, which is similar to the crack propagation process of Specimens 4 (Figure 17) in the lateral unloading test. However, the inner tips of the cracks and the outer tips of the cracks in Model 4 initiate wing cracks successively which propagate individually as unloading progresses and do not coalesce. 


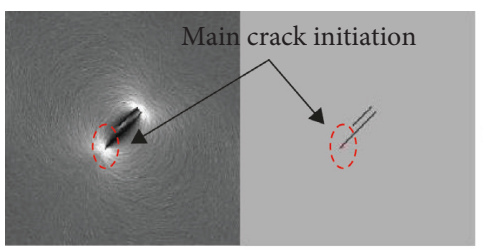

Step 15

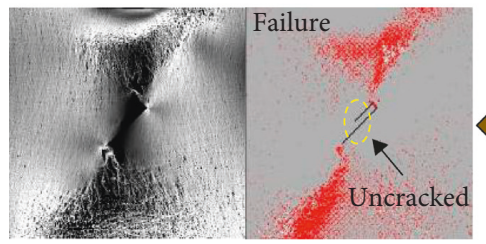

Step 30

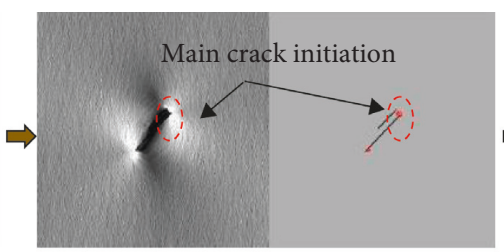

Step 18

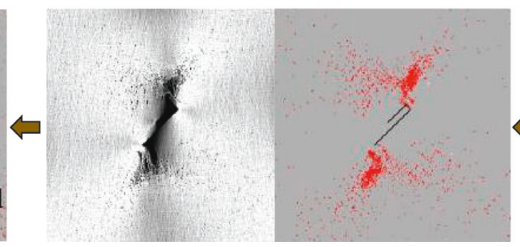

Step 27

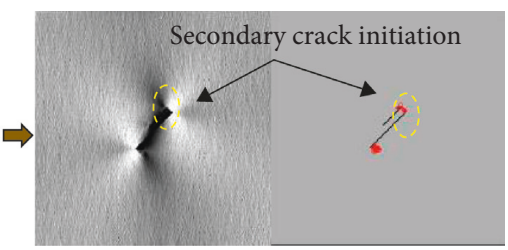

Step 19

$\sqrt{2}$

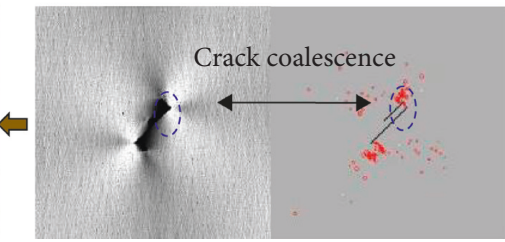

Step 25

Figure 21: Crack initiation and propagation process in Model 1.

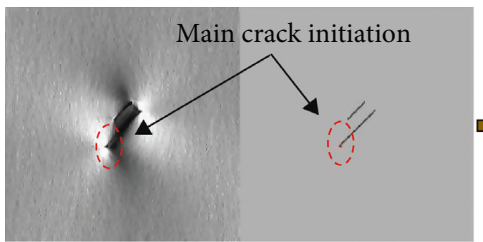

Step 14

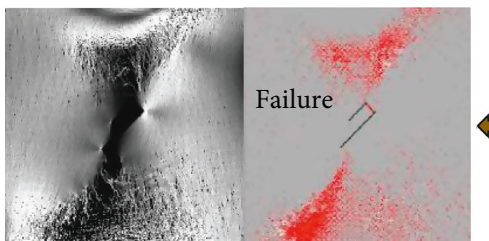

Step 32

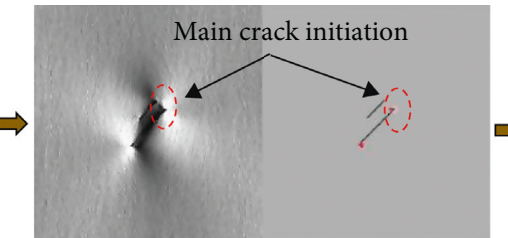

Step 16

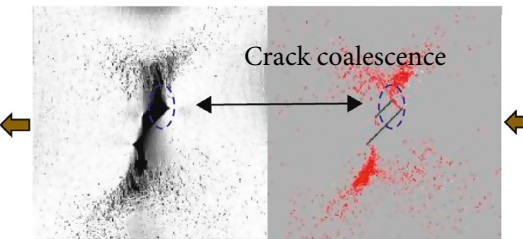

Step 28

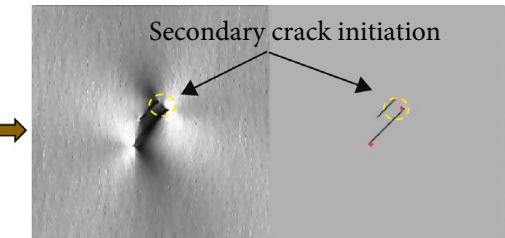

Step 18

$\sqrt{3}$

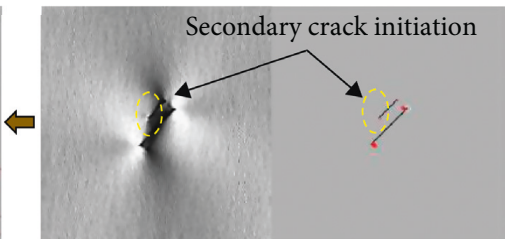

Step 21

FIgURE 22: Crack initiation and propagation process in Model 2.

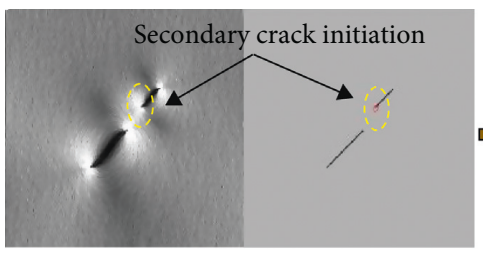

Step 16

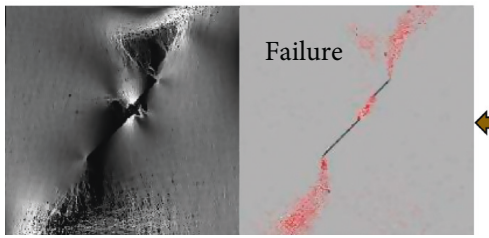

Step 29

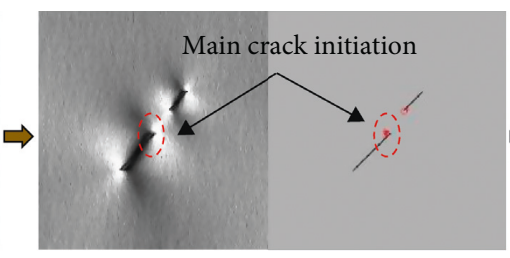

Step 18

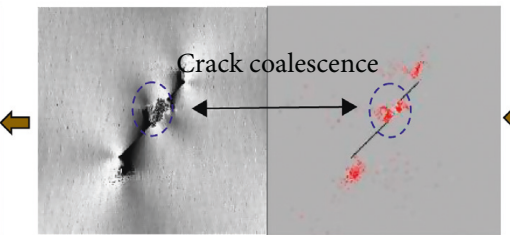

Step 26

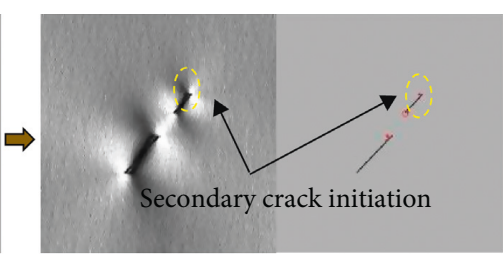

Step 19

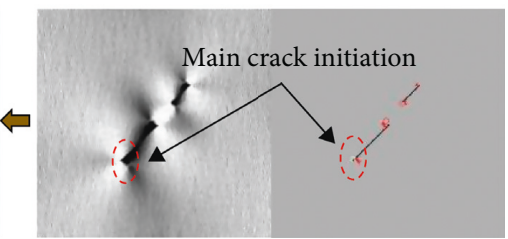

Step 20

FIgURE 23: Crack initiation and propagation process in Model 3.

By contrasting and analyzing the crack propagation phenomena of lateral unloading test and RFPA ${ }^{2 \mathrm{D}}$ numerical simulation, it can be seen that the propagation law of cracks in lateral unloading test is similar to that in numerical simulation and the interaction between cracks is weakened with the increase of staggered distance $(h)$ and length of rock 


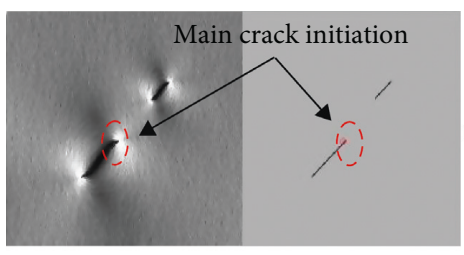

Step 18

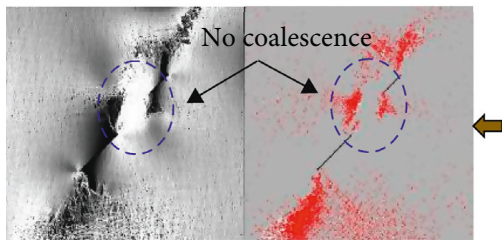

Step 33

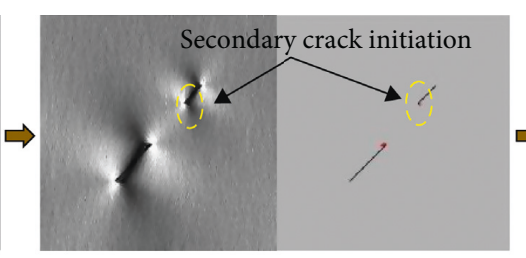

Step 20

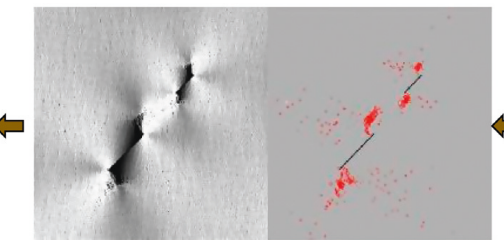

Step 28

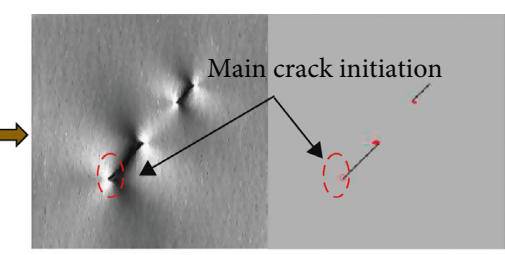

Step 22

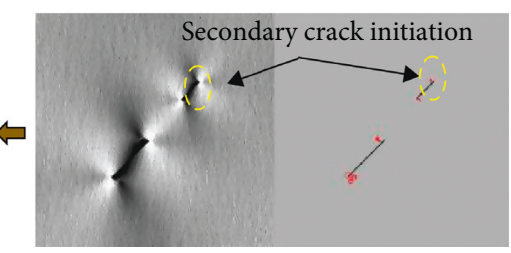

Step 23

FIgURE 24: Crack initiation and propagation process in Model 4.

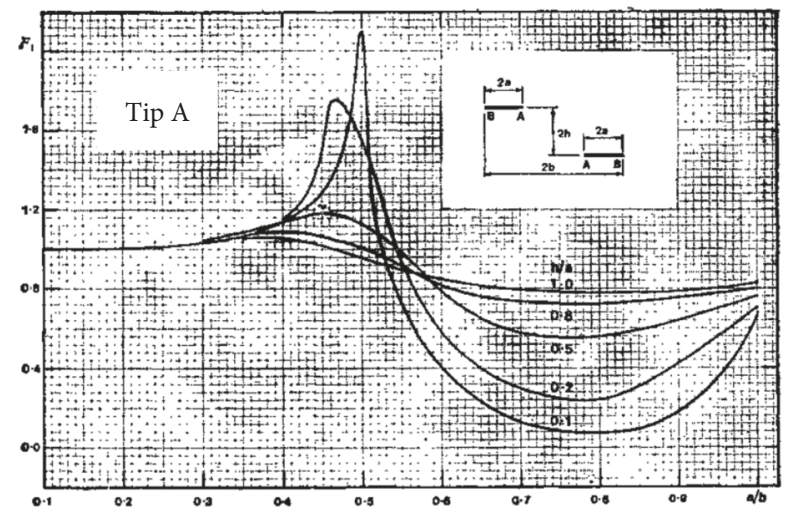

Figure 25: Values of $F_{\mathrm{I}}^{\mathrm{C}_{2}}$ and $F_{\mathrm{I}}^{D_{2}}$.

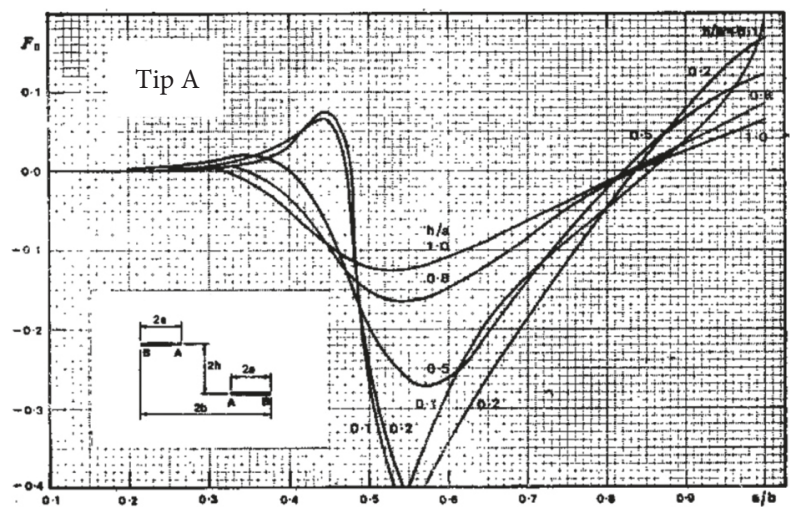

FIGURE 26: Values of $F_{\mathrm{II}}^{\mathrm{C}_{2}}$ and $F_{\mathrm{II}}^{\mathrm{D}_{2}}$.

bridge $(s)$ between cracks until ultimately becoming null. When the center distance ( $h$ and $s$ ) of the two cracks is large enough, the propagation of the two cracks is only related to their own geometric parameters and is not affected by the interaction between them. The numerical simulation phenomena are consistent with the theoretical law of the crack propagation discussed in Sections 3, which further verifies the correctness of the theory in Sections 3.

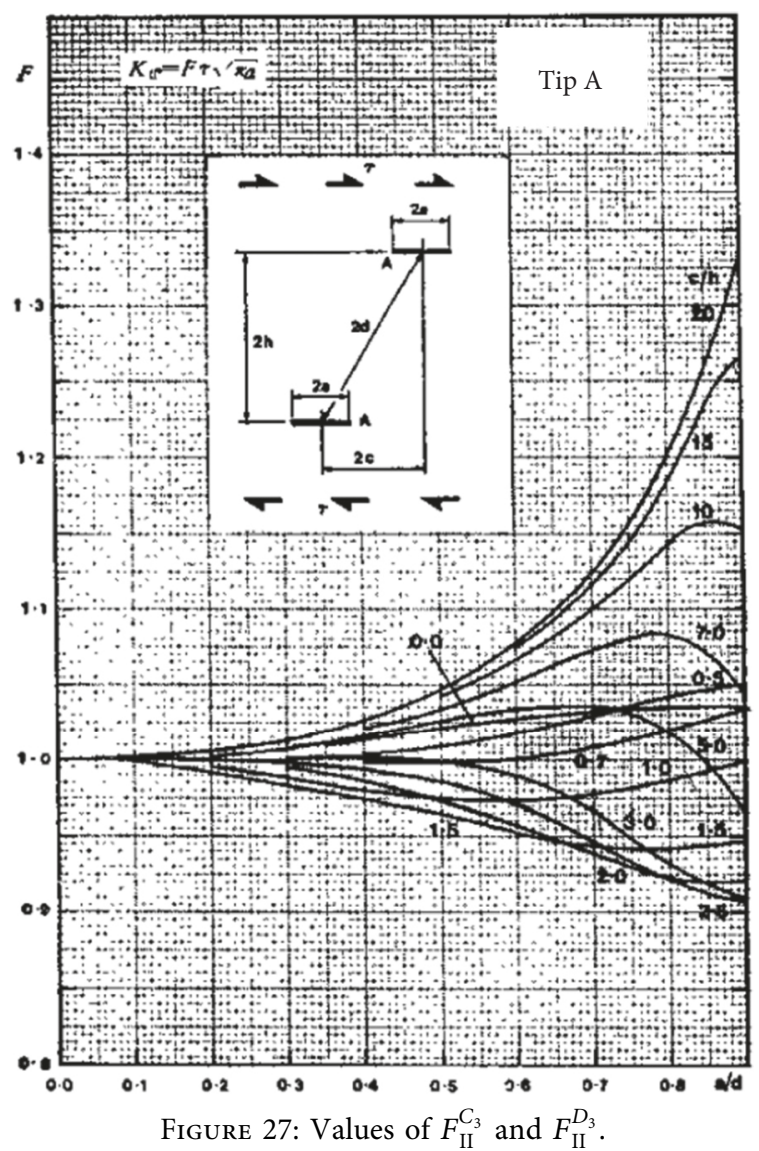

\section{Conclusions}

In this study, the propagation and interaction laws of parallel offset double cracks under unloading conditions were theoretically analyzed based on the multiple superposition principle and the relevant calculation method of SIF in fracture mechanics.

And the lateral unloading test and $\mathrm{RFPA}^{2 \mathrm{D}}$ numerical simulation were performed in order to validate the theoretical 
analysis results. The conclusions can be summarized as follows:

(1) The staggered distance and the length of the rock bridge between cracks markedly influence the crack interaction law. A larger staggered distance or length of the rock bridge between cracks produces smoother IC variation curves, indicating that the interactions are more sensitive to the center distance between when the cracks are closer together. When the staggered distance is small, the reinforcing effect on the outer tip of the crack increases at first and then weakens and gradually transforms into null effect as the length of the rock bridge increases. When the staggered distance is large, the shielding effect of Type I on the outer tip of the crack gradually weakens and transforms into reinforcing effect as the length of the rock bridge increases; the reinforcing effect on the crack tip weakens until it becomes null.

(2) The crack inclination angle $(\alpha)$ also has an important effect on the crack interaction law. The interaction strength of Type I of the inner tip of the crack is not affected by the crack inclination angle, while the shielding effect strength of Type II increases as the crack inclination angle increases, indicating that the shear-failure trend of the inner tip of the crack weakens as the crack inclination angle $(\alpha)$ increases. In addition, a smaller staggered distance between cracks makes the shear-failure trend of the inner crack tip more sensitive to the crack inclination angle $(\alpha)$. The sensitivity is highest when the angle $(\alpha)$ is around $60^{\circ}$.

(3) The lateral unloading test shows that the length of the rock bridge, staggered distance between cracks, and crack inclination angle are important factors affecting the axial peak load and axial initiation load. When the length of the rock bridge between the cracks is constant, that is, $s=|a|$ ( $a$ is length of the rock bridge and $a \geq 0$ ), the peak load and initiation load of the specimen when the length of rock bridge is negative ( $s=-a$, that is, cracks overlap) are greater than those when the length of rock bridge is positive $(s=a$, no overlap between the cracks). As the staggered distance between cracks or the inclination angle of cracks increase, the peak load and initiation load also increase.

(4) The RFPA ${ }^{2 \mathrm{D}}$ simulation results show that the propagation of the two cracks is only related to their own geometric parameters and is not affected by the interaction between them when the center distance ( $h$ and $s$ ) of the two cracks is large enough.

(5) The lateral unloading test of rock-like materials and $\mathrm{RFPA}^{2 \mathrm{D}}$ simulation produced results in close agreement with the theoretical analysis results, which validates the interaction law of parallel offset double cracks under unloading conditions as identified in the paper. It is conducive to the study of the meso-failure mechanism of the jointed rock slope in the open-pit mine under the action of excavation.

\section{Appendix}

As shown in Figures 4 and 5, the geometric correlation coefficients of SIFs in equations (3) (11) can be obtained as shown in Figures 25-27 [19].

\section{Data Availability}

The data used to support the findings of this study are available from the corresponding author upon request.

\section{Conflicts of Interest}

The authors declare that they have no conflicts of interest.

\section{Acknowledgments}

This research was supported by the National Key $R \& D$ Programs of China (Grant nos. 2016YFC0801602 and 2017YFC1503103).

\section{References}

[1] D. Huang, D. Cen, G. Ma, and R. Huang, "Step-path failure of rock slopes with intermittent joints," Landslides, vol. 12, no. 5, pp. 911-926, 2015.

[2] Y. Zhou, G. Han, S. C. Wu et al., "Meso failure mechanism of rock mass and slope with intermittent joints," Chinese Journal of Rock Mechanics and Engineering, vol. 35, no. S2, pp. 3878-3889, 2016.

[3] S. B. Tang, R. Q. Huang, C. A. Tang, Z. Z. Liang, and M. J. Heap, "The failure processes analysis of rock slope using numerical modelling techniques," Engineering Failure Analysis, vol. 79, pp. 999-1016, 2017.

[4] M. Sagong and A. Bobet, "Coalescence of multiple flaws in a rock-model material in uniaxial compression," International Journal of Rock Mechanics and Mining Sciences, vol. 39, no. 2, pp. 229-241, 2002.

[5] C. H. Park and A. Bobet, "Crack initiation, propagation and coalescence from frictional flaws in uniaxial compression," Engineering Fracture Mechanics, vol. 77, no. 14, pp. 27272748, 2010.

[6] T. L. Nguyen, S. A. Hall, P. Vacher, and G. Viggiani, "Fracture mechanisms in soft rock: identification and quantification of evolving displacement discontinuities by extended digital image correlation," Tectonophysics, vol. 503, no. 1-2, pp. 117-128, 2011.

[7] N. Y. W. Viggiani and H. Q. LI, "Numerical study on coalescence of two pre-existing coplanar flaws in rock," International Journal of Solids and Structures, vol. 50, no. 22-23, pp. 3685-3706, 2013.

[8] S. B. Tang, C. Y. Bao, and H. Y. Liu, "Brittle fracture of rock under combined tensile and compressive loading conditions," Canadian Geotechnical Journal, vol. 54, no. 1, pp. 88-101, 2017.

[9] S. B. Tang, "The effect of T-stress on the fracture of brittle rock under compression," International Journal of Rock Mechanics and Mining Sciences, vol. 79, pp. 86-98, 2015.

[10] S. B. Tang, Z. Dong, and R. Q. Huang, "Determination of T-stress using finite element analysis," Science China Technological Sciences, vol. 60, no. 8, pp. 1211-1220, 2017.

[11] C. A. Tang, P. Lin, R. H. C. Wong, and K. T. Chau, "Analysis of crack coalescence in rock-like materials containing three 
flaws-Part II: numerical approach," International Journal of Rock Mechanics and Mining Sciences, vol. 38, no. 7, pp. 925-939, 2001.

[12] R. H. C. Wong and K. T. Chau, "The coalescence of frictional cracks and the shear zone formation in brittle solids under compressive stresses," International Journal of Rock Mechanics and Mining Sciences, vol. 34, no. 3, pp. 335.e1-335.e12, 1997.

[13] A. Bobet and H. H. Einstein, "Fracture coalescence in rocktype materials under uniaxial and biaxial compression," International Journal of Rock Mechanics and Mining Sciences, vol. 35, no. 7, pp. 863-888, 1998.

[14] H. Haeri, A. Khaloo, and M. F. Marji, "A coupled experimental and numerical simulation of rock slope joints behavior," Arabian Journal of Geosciences, vol. 8, no. 9, pp. 7297-7308, 2015.

[15] Y. Zhao, L. Zhang, W. Wang, C. Pu, W. Wan, and J. Tang, "Cracking and stress-strain behavior of rock-like material containing two flaws under uniaxial compression," Rock Mechanics and Rock Engineering, vol. 49, no. 7, pp. 26652687, 2016.

[16] Q. Jiang, G. Su, X. T. Feng, G Chen, M. Z. Zhang, and C. Liu, "Excavation optimization and stability analysis for large underground caverns under high geostress: a case study of the Chinese Laxiwa project," Rock Mechanics and Rock Engineering, vol. 52, no. 3, pp. 895-915, 2019.

[17] Q. Jiang, F. Yan, J. Wu, Q. Fan, S. Li, and D. Xu, "Grading opening and shearing deformation of deep outward-dip shear belts inside high slope: a case study," Engineering Geology, vol. 250, pp. 113-129, 2019.

[18] R. Q. Huang, "Geodynamical process and stability control of high rock slope development," Chinese Journal of Rock Mechanics and Engineering, vol. 27, no. 8, pp. 1525-1544, 2008, in Chinese.

[19] L. Liu, H. B. Jia, and S. Z. Ma, “A crack damage model for rock slopes under unloading and its application," Chinese Journal of Rock Mechanics and Engineering, vol. 34, no. 4, pp. 747754, 2015.

[20] Q. Gao, Engineering Fracture Mechanics, Chongqing University Press, Chongqing, China, 1986.

[21] T. Y. Fan, Theoretical Basis of Crack, Science Press, Beijing, China, 2003.

[22] X. F. Sun, Material Mechanics, High Education Press, Beijing, China, 2013.

[23] R. Q. Huang, L. Z. Wu, and B. Li, "Crack initiation criteria and fracture simulation for precracked sandstones," Advances in Materials Science and Engineering, vol. 2019, Article ID 9359410, 12 pages, 2019.

[24] China Aeronautical Research Institute, Handbook of Stress Intensity Factors (Revised Edition), Science Press, Beijing, China, 1996.

[25] J. Y. Xi, Z. H. Chen, D. J. Zhu, and Q. F. Chen, "Stress intensity factors and initiation of unequal collinear cracks in rock," Chinese Journal of Geotechnical Engineering, vol. 37, no. 4, pp. 727-733, 2015.

[26] D. J. Zhu, Z. H. Chen, J. Y. Xi, and D. F Yang, "Interaction between offset parallel cracks in rock," Chinese Journal of Geotechnical Engineering, vol. 39, no. 2, pp. 235-243, 2017.

[27] T. C. Li, H. B. Lv, and H. Wang, "CT real-time scanning tests on double cracks propagation under uniaxial compression," Rock and Soil Mechanics, vol. 31, no. 1, pp. 9-14, 2010.

[28] R. H. C. Wong, K. T. Chau, C. A. Tang, and P. Lin, "Analysis of crack coalescence in rock-like materials containing three flaws-part I: experimental approach," International Journal of Rock Mechanics and Mining Sciences, vol. 38, no. 7, pp. 909-924, 2001.

[29] L. Y. Li, F. G. Xu, F. Gao, L. Wang, and F. X. Che, "Fracture mechanics analysis of rock bridge failure mechanism," Chinese Journal of Rock Mechanics and Engineering, vol. 24, no. 23, pp. 4328-4334, 2005.

[30] H. Manchao and Z. Fei, "Laboratory study of unloading rate effects on rockburst," Disaster Advances, vol. 6, no. 9, pp. 11-18, 2013.

[31] C. A. Tang and S. Q. Kou, "Crack propagation and coalescence in brittle materials under compression," Engineering Fracture Mechanics, vol. 61, no. 3-4, pp. 311-324, 1998.

[32] C. Tang, S. Tang, B. Gong, and H. Bai, "Discontinuous deformation and displacement analysis: from continuous to discontinuous," Science China Technological Sciences, vol. 58, no. 9, pp. 1567-1574, 2015. 


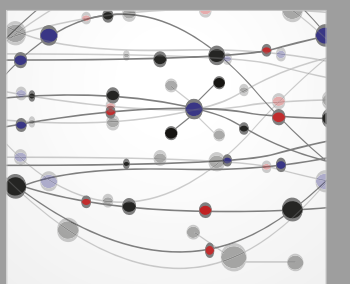

The Scientific World Journal
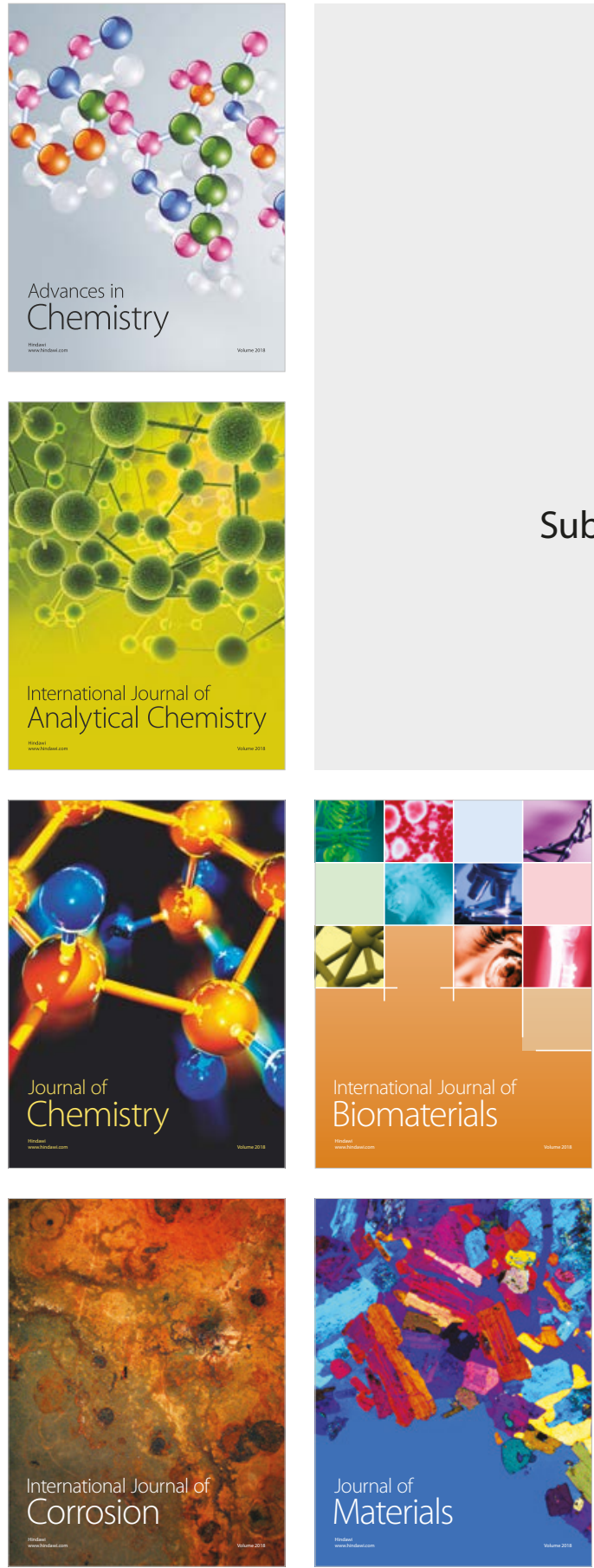

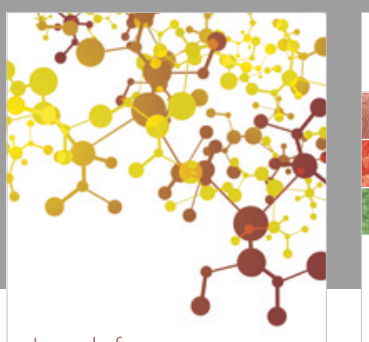

Journal of

Applied Chemistry
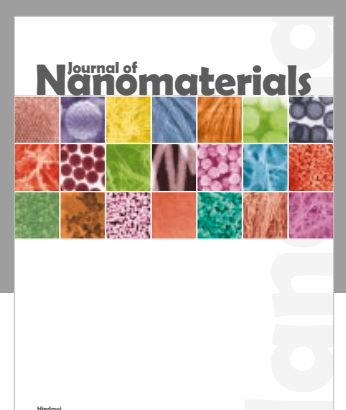

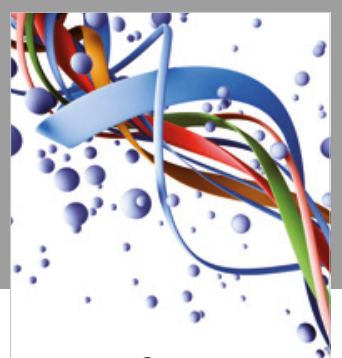

Scientifica

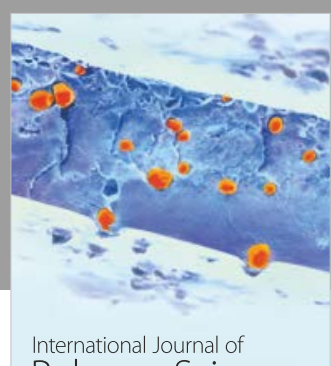

Polymer Science

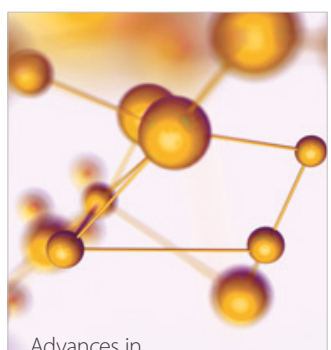

Physical Chemistry
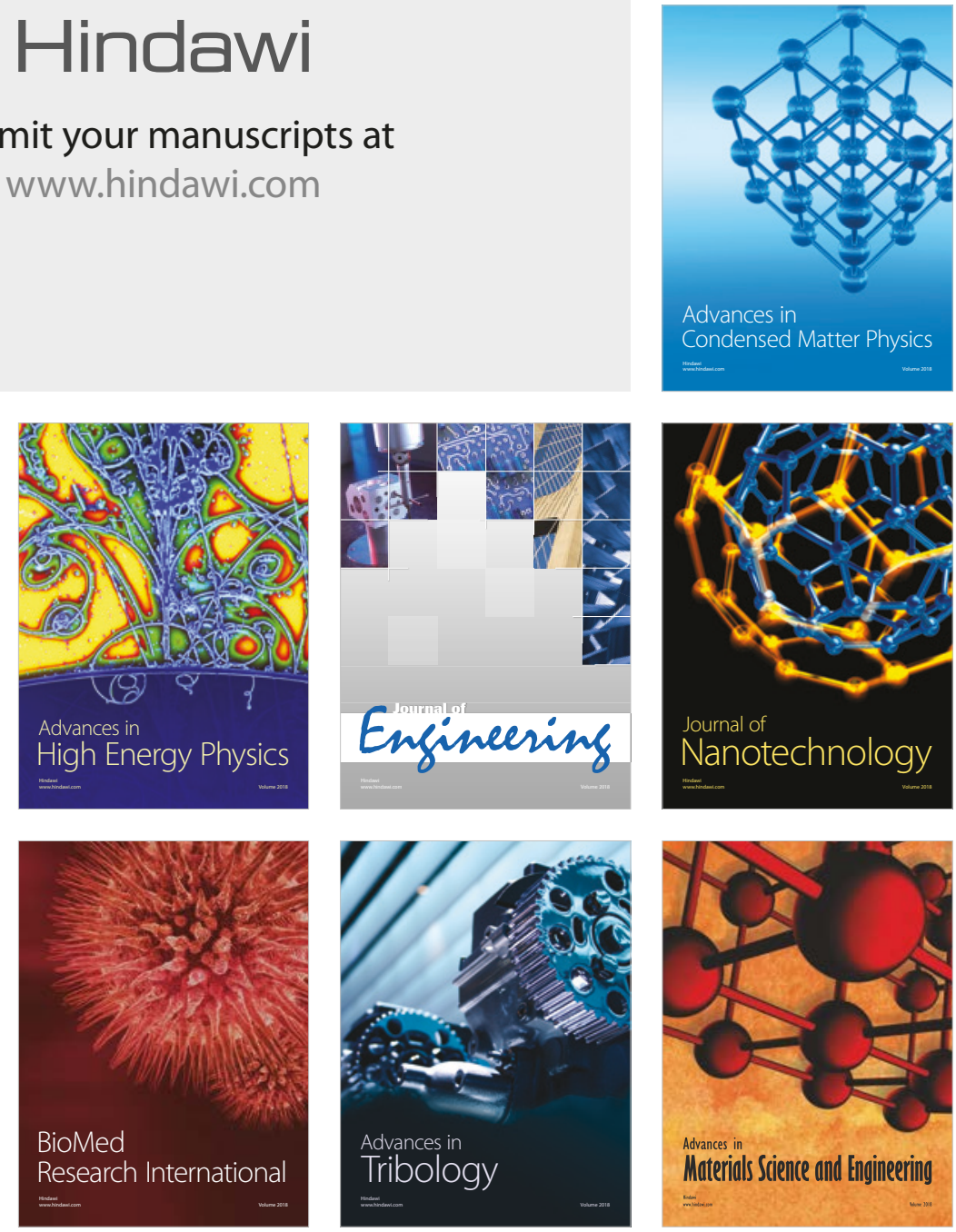